\title{
Papillary cannulation and sphincterotomy techniques at ERCP: European Society of Gastrointestinal Endoscopy (ESGE) Clinical Guideline
}

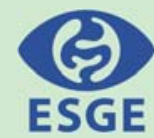

Authors

Institutions
Pier Alberto Testoni ${ }^{1}$, Alberto Mariani ${ }^{1}$, Lars Aabakken ${ }^{2}$, Marianna Arvanitakis ${ }^{3}$, Erwan Bories ${ }^{4}$, Guido Costamagna ${ }^{5}$, Jacques Devière ${ }^{3}$, Mario Dinis-Ribeiro ${ }^{6}$, Jean-Marc Dumonceau ${ }^{7}$, Marc Giovannini ${ }^{4}$, Tibor Gyokeres ${ }^{8}$, Michael Hafner ${ }^{9}$, Jorma Halttunen ${ }^{10}$, Cesare Hassan ${ }^{11}$, Luis Lopes ${ }^{12}$, Ioannis S. Papanikolaou ${ }^{13}$, Tony C. Tham ${ }^{14}$, Andrea Tringali ${ }^{5}$, Jeanin van Hooft ${ }^{15}$, Earl J. Williams ${ }^{16}$

Institutions listed at end of article.
Bibliography

DOI http://dx.doi.org/

10.1055/s-0042-108641

Published online: 14.6.2016

Endoscopy 2016; 48: 657-683

(c) Georg Thieme Verlag KG

Stuttgart · New York

ISSN 0013-726X

\section{Corresponding author}

Pier A. Testoni, MD

Division of Gastroenterology

and Gastrointestinal Endoscopy

Vita-Salute San Raffaele

University

San Raffaele Scientific Institute

Via Olgettina 60, 20132 Milan

Italy

Fax: +39-02-26433491

testoni.pieralberto@hsr.it
This Guideline is an official statement of the European Society of Gastrointestinal Endoscopy (ESGE). It provides practical advice on how to achieve successful cannulation and sphincterotomy at minimum risk to the patient. The Grading of Recommendations Assessment, Development, and Evaluation (GRADE) system was adopted to define the strength of recommendations and the quality of evidence.

\section{Main recommendations}

1 ESGE suggests that difficult biliary cannulation is defined by the presence of one or more of the following: more than 5 contacts with the papilla whilst attempting to cannulate; more than 5 minutes spent attempting to cannulate following visualization of the papilla; more than one unintended pancreatic duct cannulation or opacification (low quality evidence, weak recommendation).

2 ESGE recommends the guidewire-assisted technique for primary biliary cannulation, since it reduces the risk of post-ERCP pancreatitis (moderate quality evidence, strong recommendation).

3 ESGE recommends using pancreatic guidewire (PGW)-assisted biliary cannulation in patients where biliary cannulation is difficult and repeated unintentional access to the main pancreatic duct occurs (moderate quality evidence, strong recommendation).

ESGE recommends attempting prophylactic pancreatic stenting in all patients with PGW-assisted attempts at biliary cannulation (moderate quality evidence, strong recommendation).

4 ESGE recommends needle-knife fistulotomy as the preferred technique for precutting (moderate quality evidence, strong recommendation).

ESGE suggests that precutting should be used only by endoscopists who achieve selective biliary cannulation in more than $80 \%$ of cases using standard cannulation techniques (low quality evidence, weak recommendation).

When access to the pancreatic duct is easy to obtain, ESGE suggests placement of a pancreatic stent prior to precutting (moderate quality evidence, weak recommendation).
5 ESGE recommends that in patients with a small papilla that is difficult to cannulate, transpancreatic biliary sphincterotomy should be considered if unintentional insertion of a guidewire into the pancreatic duct occurs (moderate quality evidence, strong recommendation).

In patients who have had transpancreatic sphincterotomy, ESGE suggests prophylactic pancreatic stenting (moderate quality evidence, strong recommendation).

6 ESGE recommends that mixed current is used for sphincterotomy rather than pure cut current alone, as there is a decreased risk of mild bleeding with the former (moderate quality evidence, strong recommendation).

7 ESGE suggests endoscopic papillary balloon dilation (EPBD) as an alternative to endoscopic sphincterotomy (EST) for extracting CBD stones $<8 \mathrm{~mm}$ in patients without anatomical or clinical contraindications, especially in the presence of coagulopathy or altered anatomy (moderate quality evidence, strong recommendation).

8 ESGE does not recommend routine biliary sphincterotomy for patients undergoing pancreatic sphincterotomy, and suggests that it is reserved for patients in whom there is evidence of coexisting bile duct obstruction or biliary sphincter of Oddi dysfunction (moderate quality evidence, weak recommendation).

9 In patients with periampullary diverticulum (PAD) and difficult cannulation, ESGE suggests that pancreatic duct stent placement followed by precut sphincterotomy or needle-knife fistulotomy are suitable options to achieve cannulation (low quality evidence, weak recommendation). 
ESGE suggests that EST is safe in patients with PAD. In cases where EST is technically difficult to complete as a result of a PAD, large stone removal can be facilitated by a small EST combined with EPBD or use of EPBD alone (low quality evidence, weak recommendation).

10 For cannulation of the minor papilla, ESGE suggests using wire-guided cannulation, with or without contrast, and sphincterotomy with a pull-type sphincterotome or a needle-knife over a plastic stent (low quality evidence, weak recommendation). When cannulation of the minor papilla is difficult, ESGE suggests secretin injection, which can be preceded by methylene blue spray in the duodenum (low quality evidence, weak recommendation).

11 In patients with choledocholithiasis who are scheduled for elective cholecystectomy, ESGE suggests intraoperative ERCP with laparoendoscopic rendezvous (moderate quality evidence, weak recommendation).

ESGE suggests that when biliary cannulation is unsuccessful with a standard retrograde approach, anterograde guidewire insertion either by a percutaneous or endoscopic ultrasound (EUS)-guided approach can be used to achieve biliary access (low quality evidence, weak recommendation).

12 ESGE suggests that in patients with Billroth II gastrectomy ERCP should be performed in referral centers, with the side-viewing endoscope as a first option; forward-viewing endoscopes are the second choice in cases of failure (low quality evidence, weak recommendation).

A straight standard ERCP catheter or an inverted sphincterotome, with or without the guidewire, is recommended by ESGE for biliopancreatic cannulation in patients who have undergone Billroth II gastrectomy (low quality evidence, strong recommendation).

Endoscopic papillary ballon dilation (EPBD) is suggested as an alternative to sphincterotomy for stone extraction in the setting of patients with Billroth II gastrectomy (low quality evidence, weak recommendation).

In patients with complex post-surgical anatomy ESGE suggests referral to a center where device-assisted enteroscopy techniques are available (very low quality evidence, weak recommendation).

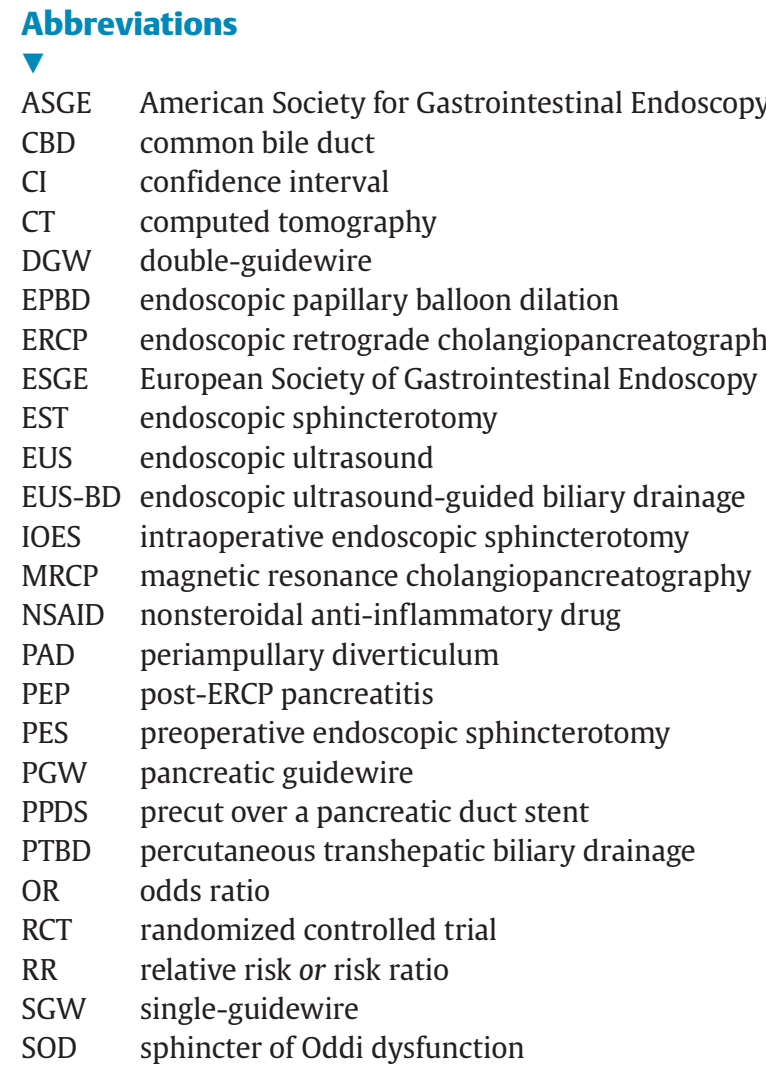

\section{Introduction}

$\nabla$

Endoscopic retrograde cholangiopancreatography (ERCP) with biliary and/or pancreatic sphincterotomy has become the preferred therapeutic option for many pancreaticobiliary conditions. Successful ERCP requires deep cannulation of the common bile duct and/or main pancreatic duct via the major duodenal papilla (papilla of Vater). Cannulation of the major papilla can be problematic: selective biliary cannulation reportedly fails in up to $18 \%$ of cases [1], though this falls to $\leq 5 \%$ in experienced hands [2]. Pancreatic duct cannulation may also be difficult in some cases. Difficulty in cannulating leads to prolonged papillary manipula- tion, and repeated attempts at cannulation, with or without injection of contrast into the pancreatic ductal system, are known to increase the risk of post-ERCP pancreatitis (PEP). In addition the effect of multiple cannulation attempts in individuals with patient-related risk factors for PEP (such as younger age or female sex) is additive.

The aim of this evidence- and consensus-based Guideline, commissioned by the European Society of Gastrointestinal Endoscopy (ESGE), is to provide practical advice on how to achieve successful cannulation and sphincterotomy at minimum risk to the patient. It considers strategies for biliary and pancreatic cannulation, intervention at the major and minor papilla, and the optimal approach for patients with altered anatomy.

\section{Methods}

$\nabla$

ESGE commissioned this Guideline and appointed a guideline leader (P.A.T.) who invited the listed authors to participate in the project development. The key questions were prepared by the coordinating team (P.A.T., A.M.), and discussed and approved by the other invited members during a preparatory meeting. The guideline development process included meetings and online discussions among members of the guideline committee from October 2014 to October 2015.Subgroups were formed, each in charge of a series of key questions ( Appendix e1, available online). A literature search of PubMed/MEDLINE, Cochrane Library, Embase, and the internet was performed by the authors for papers published up to June 2015 on this topic. The search focused on fully published prospective randomized controlled trials (RCTs) and meta-analyses. Retrospective analyses and case series were also included if they addressed topics not covered in the prospective studies. For important outcomes, articles were individually assessed by means of the Grading of Recommendations Assessment, Development, and Evaluation (GRADE) system for grading evidence levels and recommendation strengths ( $\triangle$ Appendix e2a and e2b, available online) [3]. Each subgroup developed draft proposals that were discussed via email and then presented to the Guideline committee members for general discussion during a meeting held in July 2015 (Oslo, Norway). After agreement on a final version, the manuscript was reviewed by 
two experts selected by the ESGE Governing Board and then sent to all ESGE-affiliated societies and individual members for their comments.

\section{Recommendations and statements 1. Definition of difficult biliary cannulation} $\nabla$

\begin{abstract}
ESGE suggests that difficult biliary cannulation is defined by the presence of one or more of the following: more than 5 contacts with the papilla whilst attempting to cannulate; more than 5 minutes spent attempting to cannulate following visualization of the papilla; more than one unintended pancreatic duct cannulation or opacification (low quality evidence, weak recommendation).
\end{abstract}

Selective cannulation of the common bile duct (CBD) is a prerequisite to successful biliary therapeutic interventions. Difficult cannulation is widely accepted to be a risk factor for adverse events and the following section attempts to describe the defining features of a difficult cannulation.

\subsection{What is the definition of difficult biliary cannulation? Summary of the evidence}

The definition of difficult biliary cannulation is highly variable among studies and a consensus definition is lacking. Most studies have defined a difficult biliary cannulation according to a minimum number of cannulation attempts (typically 5 to 15) or the time taken to cannulate (e.g. greater than 5 to 20 minutes). In some prospective studies, the cutoff of 10 attempts at cannulating was established because it could be demonstrated to be an independent risk factor for PEP [4-6]. This is discussed further in section 1.3. In addition to time and/or number of cannulation attempts at the papilla, unintentional passage of a guidewire or contrast injection into the pancreatic duct must also be considered, as when either of these things occur more than once this is associated with an increased risk of PEP [7]. According to a recent prospective study on 907 ERCPs performed by experienced endoscopists, the cannulation of a native papilla can be considered difficult after 5 minutes or five attempts, or more than one pancreatic cannulation [8]. ESGE suggests that this definition is used for difficult biliary cannulation.

\subsection{What factors are associated with difficult biliary cannulation?}

The likelihood of successful cannulation is influenced by operator factors (experience) and patient factors (anatomy). The supervisor should take over the endoscope from the trainee when the papilla is evaluated as difficult to cannulate (as defined in section 1.1). Both the anatomy of the papilla, such as its size, morphology, or orientation, and anatomical variants, such as presence of a large diverticulum or surgically altered anatomy, could also cause a difficult cannulation. These factors are explored in more detail in the sections that follow.

\subsection{Do papillary cannulation attempts influence the incidence of pancreatitis? \\ Summary of the evidence}

Papillary cannulation attempts have been shown to be an independent predictor of PEP when they are repeated more than 5 times or for 5 minutes [5,7,9-13]. Although there is a wide range of cutoffs defined by different studies, it is clear that the higher the number of cannulation attempts the higher the incidence of
PEP. A prospective multicenter study [5] showed a linear progression between either $\leq 3$ attempts and $4-10$ attempts, or between 4-10 and $>10$ attempts. According to a meta-analysis [11], cannulation attempts of $>10$ minutes' duration represented an independent risk factor with an odds ratio (OR) of 1.76 (95\% confidence interval $[95 \% \mathrm{CI}] 1.13-2.74)$, and the pooled incidence of PEP increased from $3.8 \%$ to $10.8 \%$ compared with cannulation attempts of $\leq 10$ minutes' duration.

\subsection{What is the single-operator learning curve for biliary} cannulation? Is it influenced by center case volume?

\section{Summary of the evidence}

The first question was the focus of a study by Verma et al.[14]. The authors evaluated retrospectively 1097 ERCP procedures performed by a single operator at a single center and showed that the successful cannulation rate increased from $43 \%$ at the beginning of training to $\geq 80 \%$ after 350 to 400 supervised procedures. The success rate continued to improve post training with an aggregated success rate of $>96 \%$ for the subsequent 300 procedures performed as an unsupervised operator. According to these authors, the consistent achievement of $\geq 80 \%$ success at deep biliary cannulation should become a standard for ERCP training programs to produce skilled and competent therapeutic biliary endoscopists. A similar rate of successful cannulation was confirmed as goal of training programs in ERCP according to the American Society for Gastrointestinal Endoscopy (ASGE) [15].

There are no data about the relationship between the learning curve for biliary cannulation and the case volume of the center; however, a relationship has been found only between center case volume and biliary therapeutic success and complications. In fact, most studies support the concept that an endoscopist's lower case volume affects outcome adversely [16]. As reported in two multicenter prospective studies, no differences were found in the rate of PEP in high volume and low volume centers and among expert and nonexpert operators [5,17]; however, the greater complexity of the patients found in more specialized centers can also play an important role.

\section{Contrast or guidewire cannulation technique}

\section{$\nabla$}

ESGE recommends the guidewire-assisted technique for primary biliary cannulation, since it reduces the risk of post-ERCP pancreatitis (moderate quality evidence, strong recommendation).

ESGE suggests that the use of a hydrophilic (tipped) guidewire for biliary cannulation can help achieve successful cannulation (very low quality evidence, weak recommendation).

Deep cannulation of the pancreaticobiliary duct during ERCP may be achieved by either injecting contrast medium or using a guidewire inserted into the ERCP cannula or sphincterotome (primary biliary cannulation). The following sections describe these techniques and their relative merits in more detail.

\subsection{How are contrast- and guidewire-assisted cannulation techniques defined?}

Contrast-assisted biliary cannulation. This involves the insertion of the tip of a sphincterotome or standard ERCP cannula into the papillary orifice in the 11-o'clock direction [18], followed by injection of a small volume of contrast under fluoroscopic guidance 
to define the anatomy of the distal bile duct. The catheter is then advanced beyond the edge of the mucosa following the " $\mathrm{S}$ " shape of the intrapapillary part of the bile duct. Most endoscopists opt to cannulate a native papilla with a sphincterotome, since the orientation to the distal biliary tree can be adjusted by pulling or relaxing the cutting wire [18]. Steerable catheters (sphincterotome or bendable) may have a higher success rate in biliary cannulation than standard cannulas [19].

Guidewire-assisted biliary cannulation. This involves cannulation of the bile duct with a guidewire prior to contrast injection [20]. The guidewire can be advanced through a sphincterotome or a standard ERCP cannula. Two different techniques have been described, but not compared:

1 The catheter is inserted into the papillary orifice and then the guidewire is advanced under fluoroscopic control $[4,6,21-23]$ in the biliary direction.

2 The guidewire is advanced $1-2 \mathrm{~mm}$ beyond the tip of the catheter and directly pushed into the papillary orifice in the axis of the common bile duct under fluoroscopic control [6,24-27].

Some experts suggest a "mixed" biliary cannulation technique whereby small volumes of contrast are injected to opacify the intraduodenal part of the common bile duct, which usually has an "S" shape, followed by gentle advancement of an angled-tip hydrophilic guidewire, in the direction previously identified by contrast injection. Unintentional injection of the pancreatic duct is limited to the very distal part of the duct and, if this occurs, after 3-5 pancreatic duct injections the operator switches to the guidewire-assisted technique as previously described [18]

\subsection{Is the guidewire-assisted technique better than the contrast-assisted technique for biliary cannulation?} Summary of the evidence

The results of biliary cannulation using contrast- and guidewireassisted biliary cannulation were evaluated in three meta-analyses [28-30] that included 5, 7 and 12 RCTs. Two of these metaanalyses $[28,29]$ also included RCTs published in abstract form only. All the meta-analyses concluded in favor of the guidewire technique in terms of a significantly higher success rate in biliary cannulation ( $\bullet$ Table 1$)$. Whether the guidewire-assisted technique also results in faster biliary cannulation is not clear as this parameter was not systematically analyzed in RCTs, and results are conflicting $[6,24,27]$. The benefit of a guidewire-based technique was demonstrated mainly in noncrossover trials [28] and heterogeneity in the RCTs also needs to be considered [29]. Specifically:

- 7/12 studies included in the most recent meta-analysis [29] allowed a switch ("crossover") to the alternative technique when the randomized one failed. The criteria used to define cannulation limits prior to crossover varied among studies, both in relation to number of attempts and time allowed to cannulate [29].

- Multiple operators (up to 15) were present in 6 out of 12 studies and trainee endoscopists were involved in 5/7 crossover studies [29].

- A sphincterotome alone was used for both the cannulation techniques in 7/12 studies; the remaining studies used standard catheters and/or sphincterotomes [29].

- Precut sphincterotomy as a rescue technique for difficult cannulation was permitted in the majority of the studies, but results among meta-analyses are variable. The guidewire-assisted technique showed a trend towards a reduced need for

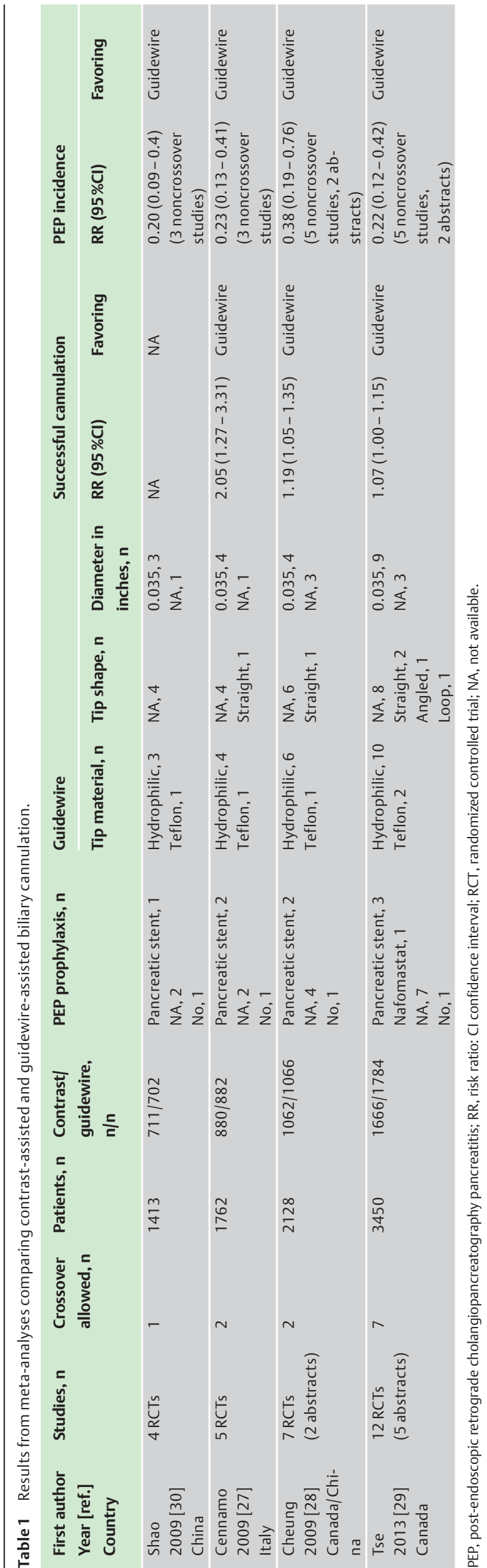


precut sphincterotomy compared with the contrast-assisted technique $[27,28]$; this difference became statistically significant in the meta-analysis that included 5 studies in abstract form [29].

Two other crossover studies $[6,26]$ have been published since the meta-analysis from Tse et al. [29]. One [6] is nonrandomized and included 4 operators, while the other [26] is an RCT involving 34 operators. These trials did not report any difference in primary biliary cannulation rate between the guidewire and contrast techniques.

In summary, when compared with the contrast technique there is evidence that guidewire-assisted biliary cannulation is associated with a higher incidence of successful cannulation. However, it is recognised that expertise of the operator and assistant need also to be considered when deciding on the preferred technique for biliary cannulation.

\subsection{For deep biliary cannulation, does the guidewire technique reduce the risk of pancreatitis compared with the contrast-assisted technique? \\ Summary of the evidence}

The risk of PEP is significantly lower with guidewire-assisted biliary cannulation according to four meta-analyses [27 - 30] ( 0 Table1). The analyses for PEP risk included noncrossover studies only, because a crossover design does not allow cases of pancreatitis to be ascribed to a single technique. The use of precutting did not increase the risk of PEP when guidewire- and contrast-assisted technique groups were compared [29]. The quality of evidence for the risk of PEP related to the cannulation technique is moderate because:

- The studies examined have a high risk of bias with regard to blinding of participants and the endoscopist [29].

- PEP definition and prophylaxis, operator experience, and trial design vary among studies [29]. In the majority, PEP was defined as "new or worsened abdominal pain lasting $>24$ hours after ERCP, with elevation of serum amylase $>3$ times above the upper limit" [31]. However, other studies did not report the definition, used an arbitrary cutoff of hyperamylasemia $>5$ times the upper limit of normal [20], or based diagnosis on the presence of computed tomography (CT) scan evidence of pancreatitis [4].

- Possible PEP prophylaxis was not addressed in most of the trials, with three studies using pancreatic stents at operator discretion and only one using a protease inhibitor ( $\bullet$ Table 1 ).

- Only crossover studies involved $>2$ expert operators and a trainee endoscopist to start the biliary cannulation.

- The threshold for use of precut as a rescue technique was not standardized, and varied in relation to number of pancreatic duct injections, guidewire cannulation of the pancreatic duct, and time allowed for successful biliary cannulation.

It should be noted that guidewire- vs. contrast-assisted cannulation may not be an independent risk factor for PEP once unintentional pancreatic duct cannulation/opacification and repeated biliary cannulation attempts are controlled for $[6,26]$. As such both biliary cannulation techniques need to be "gentle" [32] and unintentional contrast injection or guidewire insertion should be limited to the head of the pancreatic duct.

\subsection{Does success of biliary cannulation depend on the type of guidewire used? \\ Summary of the evidence}

A 0.035-inch diameter, hydrophilic-tipped guidewire is the most commonly used wire for biliary cannulation, though the shape of the tip is frequently not mentioned in published RCTs $($ Table 1$)$. One RCT compared different diameter guidewires (0.035-inch vs. 0.025-inch) with the same straight-tipped design. No difference in the success rate of primary biliary cannulation or in the risk of PEP was found. A significantly shorter radiation time was demonstrated when using the thicker guidewire, possibly due to a better radio-opacity.

No difference in the biliary cannulation success rate or PEP incidence was found when 0.035 -inch straight and angled-tipped guidewires were compared; the cannulation time was significantly shorter with the angled guidewire [34]. A recent RCT [35] compared angled and J-tipped guidewires, but the success rates for cannulation and the PEP incidence were similar.

Hydrophilic-tipped guidewires are commonly used for biliary cannulation because of the reduced friction and good pushability. The intraduodenal segment of the bile duct is usually "S"-shaped, and can be better approached with an angle-tipped guidewire. Use of an angled guidewire may facilitate biliary cannulation, but further RCTs with larger samples are awaited to confirm this result.

\section{Pancreatic guidewire-assisted biliary cannulation}

\section{$\nabla$}

ESGE recommends using pancreatic guidewire (PGW)-assisted biliary cannulation in patients where biliary cannulation is difficult and repeated unintentional access to the main pancreatic duct occurs (moderate quality evidence, strong recommendation).

ESGE recommends attempting prophylactic pancreatic stenting in all patients with PGW-assisted attempts at biliary cannulation (moderate quality evidence, strong recommendation).

\section{In the event of difficult biliary cannulation and absence of unintentional main pancreatic duct access, precutting is suggested according to papil- lary morphology. Precutting or persistent cannulation attempts present similar success and overall complication rates but PEP is less frequent when precutting is performed early (moderate quality evidence, strong recommendation).}

The so-called "pancreatic guidewire (PGW)-assisted" technique consists of leaving a guidewire in the main pancreatic duct, while attempting to cannulate the biliary duct either by using a cannula/sphincterotome with contrast medium injection (singleguidewire [SGW] technique) or by using an additional guidewire (double-guidewire [DGW] technique). A single retrospective study compared the SGW versus the DGW technique, and showed no difference in success of biliary cannulation and in PEP rates [36].

3.1 Does the pancreatic guidewire-assisted technique facilitate successful biliary cannulation in cases of difficult biliary cannulation?

Summary of the evidence

Five RCTs compared the success and complication rates of the PGW-assisted techniques vs. persistence in the standard cannulation technique (two studies), precutting (two studies), and pan- 


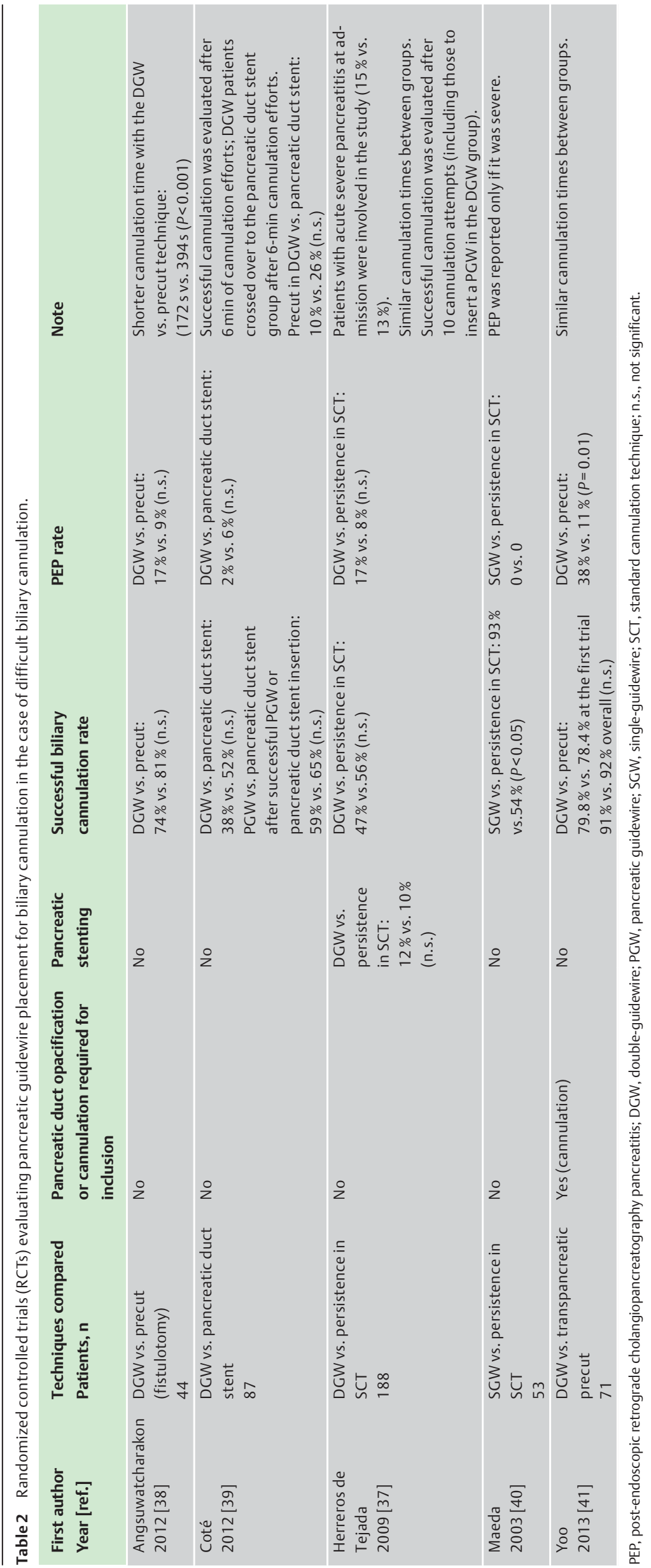


creatic stent insertion (one study) ( $\bullet$ Table 2 ) [37-41]. Of note, definitions of difficult biliary cannulation varied among studies. The only significant differences that were found were a higher success rate with the PGW-assisted technique compared with the control arm in one RCT [40], and a higher PEP rate with the PGW-assisted technique compared with the control arm in another RCT [41]. The other three RCTs showed no significant difference in either the success rate or PEP rate. A total of 443 patients were included in the five RCTs (PGW 223, and control groups 220 ), with the overall rates of successful biliary cannulation being $58.7 \%$ (PGW) vs. $62.7 \%$ (control arms) and of PEP being $13.7 \%$ (PGW) vs. 7.3\% (control arms). Prophylactic rectal nonsteroidal anti-inflammatory drugs (NSAIDs) were not used with the PGW-assisted technique and prophylactic pancreatic stenting was deployed in only 12 patients [37].

\subsection{When should PGW-assisted biliary cannulation} be used?

In all reports of PGW-assisted biliary cannulation, the technique has been reserved for use in patients with difficult biliary cannulation. Definitions of difficult biliary cannulation vary, as discussed above. The four available alternatives (persistence with standard cannulation technique, PGW-assisted cannulation techniques, precut techniques, pancreatic duct stent insertion) for achieving successful cannulation in cases of difficult biliary cannulation have yielded similar results in RCTs, as discussed in the preceding section. The sequence of recommended techniques is discussed below.

\subsection{Should PGW-assisted biliary cannulation precede precutting? \\ Summary of the evidence}

Three descriptive studies reported on a sequence of techniques for deep biliary cannulation incorporating the PGW-assisted biliary cannulation technique ( $\odot$ Table 3 ) [42-44]. The studies included 7079 patients undergoing attempted biliary cannulation. The sequence was similar in all studies: in patients with difficult biliary cannulation, PGW-assisted biliary cannulation was attempted in patients with easy pancreatic duct access (unintentional pancreatic duct cannulation or guidewire insertion), while other patients received a precut. PGW-assisted biliary cannulation succeeded in 202 (62\%) of 327 patients. In the remaining patients, the following step was a precut, preceded by an attempt at pancreatic stent insertion in two of the studies [42,43]. Precut following failed PGW-assisted biliary cannulation was successful in $82(73 \%)$ of 112 patients.
An RCT comparing PGW-assisted biliary cannulation with standard cannulation technique after 5 unsuccessful biliary cannulation attempts showed that: (a) "unintentional" common bile duct cannulation occurred in $17 \%$ of patients in the PGW-assisted group; and (b) a guidewire could not be inserted into the pancreatic duct in $19 \%$ of patients [37].

\subsection{Once a PGW has been inserted, in which cases should a pancreatic stent be inserted and when? \\ Summary of the evidence}

Prophylactic pancreatic stenting has been shown to effectively prevent PEP in high risk and mixed-case groups of patients who have undergone biliary cannulation using a variety of techniques; furthermore it is cost-effective [7]. As PGW insertion is a prerequisite for PGW-assisted attempts at biliary cannulation, prophylactic pancreatic stenting adds little time to the procedure [45]. In a study by Ito et al. 70 patients who had undergone PGW-assisted biliary cannulation were randomized to receive prophylactic pancreatic stenting or not [46]. Attempts at pancreatic stenting were successful in $91 \%$ of the patients and the stent had migrated at the end of the procedure in $3 \%$ of the patients. The frequency of PEP in the stent group was significantly lower than that in the unstented group ( $3 \%$ vs. $23 \%, P<0.05$ ). All cases of PEP were mild in severity. More recently, the same authors reported a retrospective study in which prophylactic pancreatic stenting was always attempted after PGW-assisted attempts at biliary cannulation [42]. Among 146 patients, prophylactic pancreatic stenting was successful in $86 \%$ of patients. The incidence of PEP in patients with failed prophylactic pancreatic stenting was significantly higher than in those with successful stenting (30\% vs. $5 \%, P=0.0073$ ); failed prophylactic pancreatic stenting was the only independent predictor of PEP. In another retrospective study of patients undergoing PGW-assisted biliary cannulation and biliary sphincterotomy [47] the incidence of PEP was lower in patients who received a pancreatic stent compared with those who did not (1/24 [4.2\%] vs. 9/31 [29.0\%], respectively; $P=0.031$ ). No data are available to inform the best timing for prophylactic pancreatic stenting, but if a balloon is used to clear the common bile duct, placing a pancreatic stent at the end of the procedure has the potential benefit of reducing the risk of stent displacement during ERCP maneuvers. In a retrospective study that included 142 patients who had PGW-assisted biliary cannulation, the use of a double-lumen catheter (which prevents the pancreatic duct from filling with contrast medium while a guidewire is inserted into the pancreas) was associated with a lower PEP incidence compared with a single-lumen catheter $(1 / 38$ [2.6\%] vs. $21 / 104$ [20.2\%]) [48].

Table 3 Pancreatic guidewire (PGW)-assisted biliary cannulation: sequence of biliary cannulation techniques attempted during the first ERCP session.

\begin{tabular}{|c|c|c|c|c|c|c|}
\hline \multirow{2}{*}{$\begin{array}{l}\text { First author } \\
\text { Year [ref.] }\end{array}$} & \multirow[t]{2}{*}{ Patients, $\mathbf{n}$} & \multirow{2}{*}{$\begin{array}{l}\text { Difficult biliary } \\
\text { cannulation }\end{array}$} & \multicolumn{2}{|l|}{ First-step procedure } & \multirow{2}{*}{$\begin{array}{l}\text { Successful prophylac- } \\
\text { tic pancreatic stenting }\end{array}$} & \multirow{2}{*}{$\begin{array}{l}\text { Precut following failed } \\
\text { PGW-assisted biliary } \\
\text { cannulation }\end{array}$} \\
\hline & & & $\begin{array}{l}\text { PGW-assisted biliary } \\
\text { cannulation }\end{array}$ & Precut & & \\
\hline $\begin{array}{l}\text { Ito } \\
2013[42]\end{array}$ & 4036 & NA & 146 (success 120 [80\%]) & NA & $126 / 146(86.3 \%)$ & 13 (success 6 [46\%]) \\
\hline $\begin{array}{l}\text { Lee } \\
2014[43]\end{array}$ & 711 & $140(19.7 \%)$ & 69 (success 33 [48\%]) & $\begin{array}{l}71 \\
\text { (success } 63 \text { [89\%]) }\end{array}$ & NA & 36 (success 30 [83\%]) \\
\hline $\begin{array}{l}\text { Xinopoulos } \\
2011 \text { [44] }\end{array}$ & 2332 & $179(7.7 \%)$ & 112 (success 49 [44\%]) & $\begin{array}{l}67 \\
\text { (success } 54[81 \%] \text { ) }\end{array}$ & Not attempted & 63 (success 46 [73\%]) \\
\hline
\end{tabular}

ERCP, endoscopic retrograde cholangiopancreatography; NA, not available. 
Of note, the effect of rectal NSAID administration, an intervention increasingly accepted for PEP prophylaxis [7], has not been reported on in patients subjected to PGW-assisted biliary cannulation.

\section{Precut biliary sphincterotomy}

$\nabla$

ESGE recommends needle-knife fistulotomy as the preferred technique for precutting (moderate quality evidence, strong recommendation).

ESGE suggests that precutting should be used only by endoscopists who achieve selective biliary cannulation in more than $80 \%$ of cases using standard cannulation techniques. Endoscopists who do not reach such a success rate should not be doing precuts independently (low quality evidence, weak recommendation).

When access to the pancreatic duct is easy to obtain, ESGE suggests placement of a pancreatic stent prior to precutting. It is suggested that endoscopists check for spontaneous pancreatic duct stent migration at 1 week post insertion, using abdominal X-ray (moderate quality evidence, weak recommendation).

\subsection{Definition of conventional precut and fistulotomy}

Conventional precut technique. This is usually defined as the use of a needle-knife to perform a stepwise incision of the mucosa starting at the upper margin of the papillary orifice in the direction of the bile duct until the underlying biliary sphincter is visualized.

Fistulotomy. The needle-knife fistulotomy technique is usually defined as the use of a needle-knife to perform a stepwise incision of the mucosa starting directly over the roof of the papilla followed by upward or downward cut until the underlying biliary sphincter is visualized. The goal of this technique is to avoid thermal injury to the pancreatic orifice and therefore, theoretically, reduce the risk of PEP.

\subsection{Efficacy and timing of precutting during ERCP}

The precut technique has been used to allow selective biliary cannulation in difficult cases $[49,50]$. However, it has been associated with a high risk of PEP and in many studies has been found to be an independent predictor of PEP. Precutting is often performed after repeated cannulation attempts, which raises the question as to whether it is difficult cannulation rather than the precut itself that is the true risk factor for PEP. This prompts the question as to whether early precutting is preferable to prolonged attempts at cannulation using standard techniques.

\subsubsection{Is precut biliary sphincterotomy better than} repeated papillary cannulation attempts in terms of cannulation success?

\section{Summary of the evidence}

Successful biliary cannulation following an early precut has been assessed in three meta-analyses [51-53]. Early precutting was comparable to multiple standard cannulation attempts followed by late precutting as a means to achieve deep cannulation. For example a meta-analysis from China [52] reported that primary cannulation success was $89.3 \%$ in the early precut group and $78.1 \%$ in the persistent attempts group (OR 2.05, 95\%CI $0.64-$ 6.63 ), with a similar overall final cannulation success (OR 1.54; $95 \%$ CI $0.55-4.31$ ).

It should be noted that the studies included in meta-analyses differed in the timing of the precut (immediate, or with 5,10, or 15 minutes allowed before randomization), in precut technique (at the orifice, fistulotomy, or both), and duration of persistent at-

Table 4 Meta-analyses comparing precut and conventional multiple cannulation attempts in patients with difficult biliary cannulation.

\begin{tabular}{|c|c|c|c|c|c|c|}
\hline $\begin{array}{l}\text { First author } \\
\text { Year [ref.] } \\
\text { Country }\end{array}$ & $\begin{array}{l}\text { Studies } \\
\text { Patients, n }\end{array}$ & Outcomes & $\begin{array}{l}\text { Successful } \\
\text { biliary cannu- } \\
\text { lation rate }\end{array}$ & $\begin{array}{l}\text { Complications } \\
\text { rate }\end{array}$ & Pancreatitis rate & Notes \\
\hline $\begin{array}{l}\text { Cennamo } \\
2010[51] \\
\text { Italy }\end{array}$ & $\begin{array}{l}6 \text { RCTs } \\
966 \\
-442 \text { precut } \\
-524 \text { conventional }\end{array}$ & $\begin{array}{l}\text { Success in biliary } \\
\text { cannulation } \\
\text { Complications }\end{array}$ & Similar & Similar & $\begin{array}{l}\text { Significantly lower in } \\
\text { the precut group }\end{array}$ & $\begin{array}{l}\text { Heterogeneity in the timing } \\
\text { of early precut, precut tech- } \\
\text { nique, and timing of further } \\
\text { papillary attempts after ran- } \\
\text { domization. } \\
\text { No studies used prophylac- } \\
\text { tic pancreatic stenting. }\end{array}$ \\
\hline $\begin{array}{l}\text { Gong } \\
2010[52] \\
\text { China }\end{array}$ & $\begin{array}{l}6 \text { RCTs } \\
959 \text { patients } \\
\text { - } 439 \text { precut } \\
\text { - } 520 \text { conventional }\end{array}$ & $\begin{array}{l}\text { Success in biliary } \\
\text { cannulation } \\
\text { Complications }\end{array}$ & $\begin{array}{l}\text { Similar primary } \\
\text { and final cannu- } \\
\text { lation }\end{array}$ & Similar & $\begin{array}{l}\text { Significantly lower in } \\
\text { the precut group }\end{array}$ & $\begin{array}{l}\text { No studies used prophylac- } \\
\text { tic pancreatic stenting. }\end{array}$ \\
\hline $\begin{array}{l}\text { Choudhary } \\
2014[54] \\
\text { United } \\
\text { States }\end{array}$ & $\begin{array}{l}7 \text { RCTs } \\
1032 \\
-478 \text { precut } \\
-554 \text { conventional } \\
\text { And } \\
7 \text { non-RCTs } \\
-3548\end{array}$ & $\begin{array}{l}\text { Post-ERCP pan- } \\
\text { creatitis }\end{array}$ & Not evaluated & Not evaluated & $\begin{array}{l}\text { Lower in the precut } \\
\text { group particularly if } \\
\text { done within } 5-10 \text { min } \\
\text { of failed cannulation } \\
2 / 7 \text { non-RCTs: signifi- } \\
\text { cantly lower in the } \\
\text { precut group }\end{array}$ & $\begin{array}{l}\text { Fistulotomy significantly } \\
\text { decreased the odds of PEP. } \\
\text { The NNT was } 20 \text { (pooled } \\
\text { analysis of } 2 \text { studies). } \\
\text { Excluding the single study } \\
\text { using pancreatic stenting } \\
\text { (Swan 2013) a significant } \\
\text { reduction of PEP was shown. }\end{array}$ \\
\hline $\begin{array}{l}\text { Navanee- } \\
\text { than } \\
2014[53] \\
\text { United } \\
\text { States }\end{array}$ & $\begin{array}{l}7 \text { RCTs, } \\
1039 \text { patients } \\
\text { - } 481 \text { precut } \\
\text { - } 558 \text { conventional }\end{array}$ & $\begin{array}{l}\text { Success in biliary } \\
\text { cannulation } \\
\text { Complications }\end{array}$ & Similar & Similar & $\begin{array}{l}\text { Lower in the precut } \\
\text { group }\end{array}$ & $\begin{array}{l}\text { Subgroup analysis: after } \\
\text { exclusion of } 2 \text { RCTs with im- } \\
\text { mediate precut the results } \\
\text { were unchanged. }\end{array}$ \\
\hline
\end{tabular}


tempts after randomization (from 10 to 20 minutes). Results are summarized in $\bullet$ Table 4.

\subsubsection{Is early precut biliary sphincterotomy associated with a lower incidence of PEP when compared with repeated papillary cannulation attempts?}

\section{Summary of the evidence}

Four meta-analyses investigated the risk of PEP in patients undergoing early precut compared with a prolonged standard cannulation technique [51-54]. Two meta-analyses [51,52] evaluated data from the same six RCTs, all performed in high volume centers, whereas another more recent RCT [55] was also included in the last two analyses [53,54] ( $\odot$ Table 4). A total of 966 patients were included in the six RCTs with a significantly lower rate of PEP in the early precut than in the persistent attempt group (OR $0.47,95 \% \mathrm{CI} 0-24-0.91$ ). The studies included in the meta-analyses differed as described in section 4.2.1. None of the studies evaluated in the meta-analyses were adequately powered to assess a significant PEP difference between the two methods.

The two later meta-analyses $[53,54]$ confirmed a decreased rate of PEP after early precut, but this was not statistically significant (3.9\% in the precut sphincterotomy vs. $6.1 \%$ in the persistent attempts group; OR $0.58,95 \% \mathrm{CI} 0.32-1.05 ; P=0.08$ ). When analysis was restricted to the two RCTs that employed fistulotomy, this technique significantly reduced the odds of PEP (OR $0.27,95 \% \mathrm{CI}$ $0.09-0.82 ; P=0.02$ ). This is discussed further in section 4.3.1.

4.2.3 Does the expertise of the endoscopist influence the success and adverse event rate of precut-assisted biliary sphincterotomy?

\section{Summary of the evidence}

Precut sphincterotomy has an associated learning curve. In almost all published studies the precut technique is performed by experienced endoscopists. However, most of them do not rely on precut methods in more than $10 \%-15 \%$ of cases $[56,57]$ and it is not described as a substitute for standard cannulation techniques. The need for precutting is reported to decrease with an increase in the experience of the endoscopist [56]. There is no standard definition of what constitutes expertise in precut technique.

Four retrospective [56,58-60] and two prospective [61,62] studies have examined the relation between precutting and the experience of the endoscopist. In these studies, the endoscopist precut use ranged from $5 \%$ to $31.5 \%$ of overall ERCPs (mean 18.5\%), with variation in the timing and number of cannulation attempts at the papilla before precut was performed. Five of the six published studies evaluated a single endoscopist's learning curve for precut sphincterotomy, starting at the onset of their training and following progress over a period that varied from 17 months to 8 years. The most frequently used method was to retrospectively divide the total number of precut procedures into chronologically ordered groups of similar or identical size and compare outcomes between these groups. Contradictory data were shown: in three studies [56, 58,60 ] the likelihood of successful cannulation of the bile duct correlated with endoscopist experience, whereas in three studies it did not $[59,61,62]$.

In relation to adverse events, five of six studies [56,58,60-62] were unable to demonstrate an association between experience and overall rates or grade of severity. In one study [59], the rates of immediate bleeding were significantly higher during the first 100 precuts compared with those done afterwards. On the basis of this result, the authors suggested that experience of at least 100 procedures is required to achieve competency in the technique.

In the only study [62] that compared the results of precutting between two endoscopists, no differences were observed in success and adverse events. One study [61] assessed prospectively the success and safety of precut performed by an "average" endoscopist skilled in ERCP (60-70 ERCPs per year) compared with standard biliary sphincterotomy: the adverse events, albeit with a doubled rate after precut (16.2\%), were not significantly different from those observed after standard biliary sphincterotomy $(7.7 \% ; P=0.14)$ ). Set against the reported complication rate, precut in difficult cases increased the overall success rate for selective biliary cannulation by 25 percentage points. In a recent meta-analysis including five studies (523 participants), a subgroup analysis of those three that involved only expert endoscopists (not fellows/trainees) showed a significant reduction in risk of pancreatitis (risk ratio [RR] 0.29, 95\%CI 0.10-0.86) among patients receiving early precut compared with standard technique [63].

\subsection{Conventional precut biliary sphincterotomy vs. fistulotomy \\ 4.3.1 Does precut technique influence the likelihood of successful biliary cannulation or pancreatitis?}

\section{Summary of the evidence}

Both conventional precut biliary sphincterotomy and needleknife fistulotomy are highly successful and safe when performed by experienced endoscopists from high volume centers, especially if implemented early in the procedure [51,64]. However, most studies report on a single technique, and comparative data are scarce.

A systematic review and meta-analysis was published investigating the role of early precut in the biliary cannulation strategy. Four RCTs used conventional precut, whereas two used needleknife fistulotomy. On pooled analysis, fistulotomy significantly decreased the odds of PEP $(\mathrm{OR}=0.27,95 \% \mathrm{CI} 0.09-0.82 ; P=0.02)$. Overall cannulation rates were comparable between both precut techniques [54]. In an RCT of 153 patients, comparing two precut techniques in the management of choledocholithiasis, the rate of PEP was significantly lower after fistulotomy $(0 \%)$ compared with conventional precut (7.59\%) [65]. In a retrospective study comparing three precut techniques, in which the selection of the precut technique was based on papillary morphology, the outcomes of 274 patients were assessed. The PEP rate was significantly lower in patients allocated to fistulotomy rather than to conventional precut (2.6\% vs. $20.9 \%$ ) [66]. In another retrospective study comparing two precut techniques, performed by three experienced endoscopists, a nonsignificant trend to a lower rate of PEP was observed after fistulotomy ( $0 \%$ ) compared with two variations of the conventional precut (12.8\% and 6.3\%) [67]. However in this study there were differences between endoscopists in terms of electrosurgical current used and pancreatic stenting policy.

\subsubsection{Does papillary morphology influence the choice} of precut technique?

\section{Summary of the evidence}

The vast majority of endoscopists perform the same type of precut over time, irrespective of the morphology of the papilla. There are no randomized controlled trials or prospective cohort studies comparing the success and safety of the two precut techniques in relation to papillary morphology. Two retrospective co- 
hort studies compared three precut techniques, in which the selected precut was determined by the papillary morphology, based on personal preferences of the endoscopists: fistulotomy was reserved for papillas in which the intraduodenal segment of the common bile duct bulged on the medial duodenal wall [66, 68].

During ERCP it would be useful if we could predict the diameter of the bile duct based on endoscopic findings, as needle-knife fistulotomy seems to be safer in patients with large distal bile ducts. However there are no studies addressing the value of papillary morphology as a predictor of the diameter of the distal CBD.

\subsection{The role of precutting following pancreatic stent placement \\ Summary of the evidence}

Prolonged attempts at cannulation have been linked with an increased risk of PEP $[7,8,69]$. This suggests that after a number of failed attempts to achieve deep biliary cannulation (varying from 3 to 10 in studies $[7,8,69,70]$ ), alternative strategies must be pursued, including conventional "freehand" needle-knife precut papillotomy (the technique used most often), precut fistulotomy, the DGW cannulation technique, or transpancreatic sphincterotomy with or without placement of a pancreatic duct stent. The rationale behind performance of precutting over a pancreatic duct stent (PPDS) is the facilitation of biliary cannulation by using the stent as a guide for precutting whilst reducing the incidence of PEP $[7,18,43,69,71]$. As such, the ESGE Guideline for PEP prophylaxis [7] recommends that, when needle-knife precut papillotomy is undertaken and pancreatic cannulation is easily obtained, a small-diameter (usually 3-Fr or 5-Fr) pancreatic duct stent should be placed to guide the cut, and that the stent should be left in place at the end of the procedure.

\subsubsection{Does precut over a pancreatic stent improve the} success rate and reduce the adverse event rate compared with the conventional precut technique?

\section{Summary of the evidence}

A recent study tested the efficacy, feasibility and safety of PPDS compared with freehand needle-knife precut papillotomy, by analyzing retrospective data from an ERCP cohort where precutting was performed in cases of difficult biliary cannulation [71]. Out of 1619 patients with naive papillas, precutting was undertaken in $8.3 \%$ (total 134: needle-knife papillotomy 36 patients, PPDS 98 patients). Biliary cannulation success rates were significantly better for PPDS compared with the conventional needleknife technique (95/98 [96.9\%] vs. 31/36 [86.1\%]; $P=0.0189)$. In terms of overall adverse events, PPDS also performed better than conventional needle-knife (7/98 [7.1\%] vs. 12/36 [33\%] including 1 fatal bleed; $P<0.001)$. Major limitations of this study were its retrospective design and a chronological bias in favor of PPDS.

In another trial that included 151 consecutive patients, after successful PPDS, patients were randomized to having the pancreatic duct stent in situ for $7-10$ days $(n=46)$ or having the stent removed post-procedurally $(n=47)$ [72]. PEP rates were significantly lower in the group where the pancreatic duct stent was left in situ ( $4.3 \%$ vs. $21.3 \%, P=0.027$ ).

Other studies did not answer the main key question, but did address some of its aspects. In a study by Madácsy et al. [73], 22 patients with sphincter of Oddi dysfunction (SOD) and difficult cannulation, who underwent early prophylactic pancreatic duct stenting followed by fistulotomy, were compared with a retro- spective cohort of 35 SOD patients where repeated standard cannulation (with a pull-type sphincterotome) was attempted. Fistulotomy with the pancreatic duct stent in situ was safer than conventional pull-type biliary sphincterotomy (PEP rates, respectively, $0 \%$ vs. $43 \%$; $P<0.001$ ). Similar findings have been reported elsewhere [74] though the results for patients undergoing pancreatic or minor papilla sphincterotomy are conflicting [75-78]. In terms of choice of stent, most authors reported using short 3 6-Fr devices with external pigtails or flanges. Stents without the internal flange tend to migrate spontaneously after the procedure $[18,39,69]$. A recent meta-analysis on pancreatic duct stenting to prevent PEP in a mixed population of high risk patients reported that 5-Fr stents were superior to 3-Fr stents [79], and, given that PPDS is most likely to be used after unintentional pancreatic duct cannulation with a standard 0.035 -inch guidewire, this seems to be an appropriate option. The stent should be left in the pancreatic duct for at least $12-24$ hours to reduce the risk for PEP [7].

\section{Transpancreatic biliary sphincterotomy \\ 7}

ESGE recommends that in patients with a small papilla that is difficult to cannulate, transpancreatic biliary sphincterotomy should be considered if unintentional insertion of a guidewire into the pancreatic duct occurs. However this technique should only be performed by experts (moderate quality evidence, strong recommendation).

In patients who have had transpancreatic sphincterotomy, ESGE suggests prophylactic pancreatic stenting (moderate quality evidence, strong recommendation).

Transpancreatic biliary sphincterotomy (TPBS) is a technique for cannulating the bile duct when usual methods fail [80]. It involves the placement of a standard "traction-type" papillotome on a guidewire previously inserted into the main pancreatic duct. A sphincterotomy is performed in the direction of the bile duct at an 11-12-o'clock position. The aim is to make an incision through the septum between the pancreatic and biliary duct and to expose the bile duct orifice. After this, the sphincterotomy is extended to expose the biliary lumen and the biliary duct can be cannulated. The biliary orifice can be found either at the apex of the incision, immediately left of the pancreatic orifice (in patients with a "common channel") or at the starting point of the incision along the left edge (in patients with separate pancreatic and biliary orifices). TPBS is a technique usually performed only by endoscopists experienced in ERCP.

\subsection{Success and adverse events following transpancreatic biliary sphincterotomy Summary of the evidence}

Four RCTs [41,81 - 83] involving a total of 364 patients have investigated the outcome of TPBS. Only one was a multicenter study and this was published in abstract form [82]. Table 5 summarizes the results of these trials and of the two prospective nonrandomized studies examining TPBS $[84,85]$. In combination with the three largest retrospective series (each $>200$ patients) [86-88], these studies suggest that the rate of successful biliary cannulation following TPBS ranges from $85 \%$ to $100 \%$ (median $92.9 \%$ ), and the rate of adverse events ranges from $3.5 \%$ to $20.5 \%$ (median $13.1 \%$ ), with PEP occurring in $3.5 \%$ to $22.4 \%$ of cases (median $10.4 \%$ ). One 
Table 5 Randomized controlled trials (RCTs) and prospective studies comparing transpancreatic biliary sphincterotomy (TPBS) and other techniques in patients with difficult biliary cannulation.

\begin{tabular}{|c|c|c|c|c|c|c|c|}
\hline $\begin{array}{l}\text { First author } \\
\text { Year [ref.] } \\
\text { Country }\end{array}$ & $\begin{array}{l}\text { Study design } \\
\text { Patients, } \mathrm{n}\end{array}$ & $\begin{array}{l}\text { Compara- } \\
\text { tive tech- } \\
\text { nique in } \\
\text { controls }\end{array}$ & Outcomes & $\begin{array}{l}\text { Successful } \\
\text { biliary cannu- } \\
\text { lation rate }\end{array}$ & $\begin{array}{l}\text { Complica- } \\
\text { tions rate }\end{array}$ & $\begin{array}{l}\text { Pancreatitis } \\
\text { rate }\end{array}$ & Notes \\
\hline $\begin{array}{l}\text { Zang } \\
2014[81] \\
\text { China }\end{array}$ & $\begin{array}{l}\text { RCT, single- } \\
\text { center } \\
149\end{array}$ & NKS & $\begin{array}{l}\text { Success in biliary } \\
\text { cannulation } \\
\text { Cannulation time } \\
\text { Complications }\end{array}$ & $\begin{array}{l}\text { Higher in TPBS } \\
(P=0.018)\end{array}$ & Similar & Similar & $\begin{array}{l}\text { No pancreatic stent } \\
\text { Shorter cannulation time in } \\
\text { TPBS group }(P<0.001)\end{array}$ \\
\hline $\begin{array}{l}\text { Yoo } \\
2013[41] \\
\text { Korea }\end{array}$ & $\begin{array}{l}\text { RCT, single- } \\
\text { center } \\
71\end{array}$ & DGW & $\begin{array}{l}\text { Success in biliary } \\
\text { cannulation } \\
\text { Cannulation time } \\
\text { Complications }\end{array}$ & Similar & $\begin{array}{l}\text { Higher in } \\
\text { DGW } \\
(P<0.01)\end{array}$ & $\begin{array}{l}\text { Higher in } \\
\text { DGW } \\
(P<0.011)\end{array}$ & $\begin{array}{l}\text { No pancreatic stent } \\
\text { Pancreatic duct contrast } \\
\text { injection in most patients }\end{array}$ \\
\hline $\begin{array}{l}\text { Chun } \\
2012[82] \\
\text { (abstract) } \\
\text { Korea }\end{array}$ & $\begin{array}{l}\text { RCT, } \\
\text { multicenter } \\
81\end{array}$ & DGW & $\begin{array}{l}\text { Success in biliary } \\
\text { cannulation } \\
\text { Complications }\end{array}$ & Similar & Not reported & Similar & $\begin{array}{l}\text { Mean cannulation time: } \\
\text { trend towards TPBS ( } 15 \text { vs. } \\
19.7 \text { min; } P=0.054 \text { ) }\end{array}$ \\
\hline $\begin{array}{l}\text { Catalano } \\
2004[83] \\
\text { USA }\end{array}$ & $\begin{array}{l}\text { RCT, single- } \\
\text { center } \\
63\end{array}$ & NKS & $\begin{array}{l}\text { Success in biliary } \\
\text { cannulation } \\
\text { Complications }\end{array}$ & $\begin{array}{l}\text { Higher in TPBS } \\
(P=0.01)\end{array}$ & Similar & Similar & $\begin{array}{l}\text { Pancreatic stent at discre- } \\
\text { tion of endoscopist }\end{array}$ \\
\hline $\begin{array}{l}\text { Kahaleh } \\
2004[84] \\
\text { USA }\end{array}$ & $\begin{array}{l}\text { Prospective, } \\
\text { single-center } \\
236\end{array}$ & EST & $\begin{array}{l}\text { Success in biliary } \\
\text { cannulation (only in } \\
\text { TPBS group) } \\
\text { Complications }\end{array}$ & $\begin{array}{l}\text { Immediate } \\
\text { biliary access in } \\
\text { TPBS: } \\
85 \%\end{array}$ & Similar & Similar & $\begin{array}{l}\text { Access time } \leq 10 \text { min after } \\
\text { TPBS was associated with } \\
\text { successful biliary cannula- } \\
\text { tion }\end{array}$ \\
\hline $\begin{array}{l}\text { Lee } \\
2015 \text { [85] } \\
\text { Korea }\end{array}$ & $\begin{array}{l}\text { Prospective, } \\
\text { single-center } \\
86\end{array}$ & NKS & $\begin{array}{l}\text { Success in biliary } \\
\text { cannulation } \\
\text { Complications }\end{array}$ & Similar & Similar & Similar & $\begin{array}{l}\text { TPBS if pancreatic duct } \\
\text { cannulation, NKS if no } \\
\text { pancreatic duct cannula- } \\
\text { tion } \\
\text { Crossover TPBS-NKS } \\
\text { No pancreatic stent }\end{array}$ \\
\hline
\end{tabular}

NKS, needle-knife sphincterotomy; DGW double-guidewire; EST, endoscopic biliary sphincterotomy.

of the two prospective studies [84] showed that in expert hands, success correlated to the speed of biliary access after TPBS.

\subsection{When should transpancreatic biliary sphincterotomy be performed?}

TPBS is a technique that should be reserved for patients with difficult biliary cannulation (see definition above) where attempts at standard and DGW cannulation have failed. There are no data to guide endoscopists when selecting between TPBS and precutting. In the presence of a small papilla, TPBS has a theoretical advantage in that the depth and location of incision in relation to the CBD is more controlled than with needle-knife sphincterotomy. Conversely, in the presence of a protuberant papilla with a visible intraduodenal CBD segment, needle-knife sphincterotomy may be easier to perform safely. When TPBS is selected first and is unsuccessful, a crossover to needle-knife sphincterotomy would appear reasonable. Finally it should be noted that no studies have compared the strategy of a second ERCP with TPBS in terms of safety and efficacy.

\subsection{Should pancreatic stenting be performed to prevent pancreatitis in patients undergoing transpancreatic biliary sphincterotomy?}

With regard to patients undergoing needle-knife sphincterotomy, no studies have been published addressing this question. An ESGE Clinical Guideline [7] strongly recommends the placement of a pancreatic stent after TPBS. Some experts suggest use of a flanged pancreatic stent to avoid early migration of the stent following pancreatic sphincter ablation.
An evidence-based algorithm for biliary cannulation during ERCP in difficult cases is described in $\bullet$ Fig. 1.

\section{Biliary sphincterotomy: pure cut vs. mixed current}

ESGE recommends that mixed current is used for sphincterotomy rather than pure cut current alone, as there is a decreased risk of mild bleeding with the former (moderate quality evidence, strong recommendation).

ESGE suggests that a current mode that provides alternating cutting and coagulation phases (e.g. Endocut or Pulsecut) is used instead of conventional blended current, as it may be associated with fewer episodes of uncontrolled cutting ("zippers") and a lower risk of bleeding at the time of sphincterotomy (moderate quality evidence, weak recommendation).

The characteristics of the electrosurgical current may affect the frequency and extent of the adverse events of endoscopic sphincterotomy because the nature of thermal tissue injury depends on the characteristics of the electrosurgical current used to perform the sphincterotomy. A pure cutting current achieves better cutting ability. A low voltage coagulating current achieves better hemostasis but it is not used alone for sphincterotomy. A mixed current comprising mixed patterns of both pure cutting and coagulating currents is available in two modes: the blended cut and a current mode that provides alternating cutting and coagulation phases (e.g. Endocut or Pulsecut mode). The blended cut mode comprises cutting and coagulating currents delivered together in one waveform, whereas in the Endocut mode (ERBE, Marietta, 


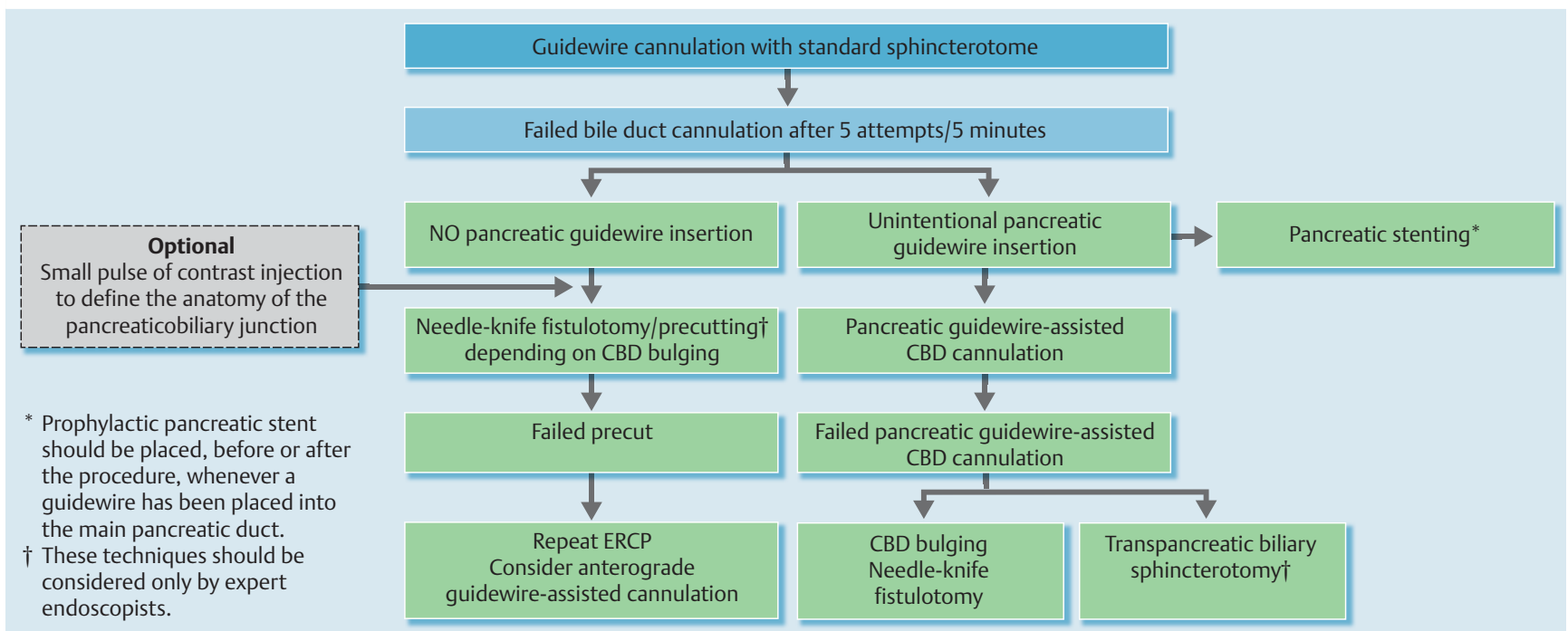

Fig. 1 Evidence-based algorithm for biliary cannulation in endoscopic retrograde cholangiopancreatography (ERCP). CBD, common bile duct.

Georgia, USA) or Pulsecut mode (Olympus Europe, Hamburg, Germany) the cutting and coagulating currents are applied in turn in short bursts with an intermittent pause.

\subsection{Is there any difference in adverse events following biliary sphincterotomy using pure cut vs. mixed current? Summary of the evidence}

When compared with the conventional blended mode, the Endocut or Pulsecut can in theory prevent perforation of the superior part of the papilla by avoiding an uncontrolled cutting speed because of their automatically fractionated cut. However, no statistically significant difference in the rate of adverse events, including PEP or bleeding, has been observed when the two modes have been compared in trials. Nonetheless Endocut or Pulsecut mode were associated with fewer "zippers," i.e., uncontrolled cutting and bleeding at the time of sphincterotomy [89-93]. Therefore, these two forms of mixed current can be grouped together to compare with pure cutting current.

Out of five RCTs [94-98], two found a significantly lower rate of pancreatitis with pure cutting compared with mixed current [94, 95]. Pure cutting current was associated with more episodes of bleeding, primarily mild bleeding which did not translate into increased morbidity or mortality [94-98]. These findings were partially supported by a meta-analysis of four of these studies: mild bleeding was confirmed significantly more frequently with pure current compared with mixed current; pancreatitis was similar with the two modes [99]. There were insufficient data to analyze the perforation risk of pure vs. mixed current.

\section{Endoscopic papillary balloon dilation as an alternative to biliary sphincterotomy}

ESGE suggests endoscopic papillary balloon dilation (EPBD) as an alternative to endoscopic sphincterotomy (EST) for extracting CBD stones $<8 \mathrm{~mm}$ in patients without anatomical or clinical contraindications (e.g. acute pancreatitis, acute cholangitis, or precut sphincterotomy), especially in the presence of coagulopathy or altered anatomy (moderate quality evidence, strong recommendation).
For performance of EPBD, a 8-mm diameter balloon is recommended irrespective of the CBD diameter, and papillary dilation following waist disappearance should last for a minimum of 2 minutes. Data on the duration of dilation are conflicting, but 1 minute of dilation may have a higher rate of complications than 5 minutes (high quality evidence, weak recommendation).

Although data comparing the incidence of PEP after balloon dilation or sphincterotomy are lacking, experts recommend creation of a short biliary sphincterotomy before dilation to reduce the risk of PEP (low quality evidence, weak recommendation).

Choledocholithiasis is the only indication for endoscopic papillary balloon dilation (EPBD) reported in large controlled series. Widely accepted contraindications include biliary strictures or ampullary/pancreatic/biliary malignancies, prior biliary surgery except cholecystectomy, acute pancreatitis, acute cholangitis, precut sphincterotomy for biliary access, and large CBD stones. Balloons measuring $8 \mathrm{~mm}$ in diameter were used in most RCTs, irrespective of the CBD diameter. Three recent meta-analyses of RCTs were considered in order to assess the efficacy and morbidity of EPBD vs. EST [100 - 102] ( Table 6).

- With respect to success of biliary stone extraction, EPBD yielded roughly similar rates of complete stone removal but more frequently required endoscopic mechanical lithotripsy than EST. In an RCT that did not exclude large CBD stones, failure of CBD stone extraction was closely related to large CBD stone diameter [103].

- With respect to short-term morbidity, no significant difference was found in overall morbidity rates between EPBD and EST. A network meta-analysis showed that the relative probabilities of being the safest treatment in relation to PEP were: long EPBD $43.9 \%$, short EPBD 0.2\%, and EST 55.9\%. The relative probabilities of being the safest treatment in relation to overall complications were: long EPBD 90.3\%, short EPBD 1.3\%, and EST 8.4\% [100].

- With respect to long-term morbidity, compared with EST, EPBD was associated with a lower incidence of overall adverse events, of acute cholecystitis, and of biliary stone recurrence; ORs were close to 0.5 for these three items. Similar findings were reported in RCTs not included in the meta-analysis and in large retrospective studies. 
Table 6 Recent meta-analyses of randomized controlled trials (RCTs) comparing endoscopic papillary balloon dilation (EPBD) vs. endoscopic sphincterotomy (EST) for extracting common bile duct stones.

\begin{tabular}{|c|c|c|c|c|}
\hline \multirow{2}{*}{$\begin{array}{l}\text { First author } \\
\text { Year [ref.] }\end{array}$} & \multirow{2}{*}{$\begin{array}{l}\text { Studies } \\
\text { Intervention }\end{array}$} & \multirow{2}{*}{$\begin{array}{l}\text { Patients, n } \\
\text { (Dates) }\end{array}$} & \multicolumn{2}{|l|}{ Outcomes, EPBD vs. EST } \\
\hline & & & Success rates & Complications \\
\hline $\begin{array}{l}\text { Liao } \\
2012 \text { [100] }\end{array}$ & $\begin{array}{l}4 \text { RCTs } \\
\text { Short EPBD vs. EST } \\
7 \text { RCTs } \\
\text { Long EPBD vs. EST } \\
\text { (Balloon } \leq 10 \mathrm{~mm} \text { ) } \\
\text { Short vs. long } \\
\text { dilation } \\
\text { (1 min vs. } 5 \mathrm{~min}\end{array}$ & $\begin{array}{l}923 \\
-459 \text { vs. } 464 \\
556 \\
-277 \text { vs. } 279 \\
170 \\
-86 \text { vs. } 84 \\
(1995-2010)\end{array}$ & NA & $\begin{array}{l}\text { Short-term complications } \\
\text { Overall incidence: } \\
\text { - Short EPBD: OR } 1.71,95 \% \mathrm{Cl} 0.67-4.35 \\
\text { - Long EPBD: OR } 0.61,95 \% \mathrm{Cl} 0.36-1.04 \\
\text { PEP: } \\
\text { - Short EPBD: OR } 3.87,95 \% \mathrm{Cl} 1.08 \text { - } \\
\quad 13.84 \\
\text { - Long EPBD: OR } 1.14,95 \% \mathrm{Cl} 0.56-2.35 \\
\text { Note: see text for details about the addi- } \\
\text { tional network meta-analysis }\end{array}$ \\
\hline $\begin{array}{l}\text { Liu, } \\
2012 \text { [101] }\end{array}$ & $\begin{array}{l}10 \text { RCTs } \\
\text { EPBD vs. EST } \\
\text { (Balloon } \leq 10 \mathrm{~mm} \text { ) }\end{array}$ & $\begin{array}{l}1451 \\
-724 \text { vs. } 727 \\
(2001-2007)\end{array}$ & $\begin{array}{l}\text { Complete stone removal: } \\
\text { - } 94.6 \% \text { vs. } 95.9 \% \text { (n.s.) } \\
\text { EML: } \\
-35.0 \% \text { vs. } 26.2 \%(P=0.0004)\end{array}$ & $\begin{array}{l}\text { Short-term complications } \\
\text { Overall incidence: } \\
\text { - } 14.0 \% \text { vs. } 11.7 \% \text { (n.s.) } \\
\text { PEP: } \\
\text { - } 9.4 \% \text { vs. } 3.3 \%(P<0.00001) \\
\text { Bleeding: } \\
\text { - } 0.1 \% \text { vs. } 4.2 \%(P<0.00001) \\
\text { Cholangitis, basket impaction, and } \\
\text { perforation: } \\
\text { - n.s. }\end{array}$ \\
\hline $\begin{array}{l}\text { Zhao } \\
2013 \text { [102] }\end{array}$ & $\begin{array}{l}14 \text { RCTs } \\
\text { EPBD vs. EST } \\
(\text { Balloon } \leq 10 \mathrm{~mm} \text { ) }\end{array}$ & $\begin{array}{l}1975 \\
-980 \text { vs. } 995 \\
(1995-2010)\end{array}$ & $\begin{array}{l}\text { Complete stone removal: } \\
\text { - } 92.4 \% \text { vs. } 95.1 \% \text { (OR } 0.6495 \% \mathrm{Cl} \\
\quad 0.42-0.96 \text { ) } \\
\text { Use of extraction baskets: } \\
\text { - OR } 1.91,95 \% \mathrm{Cl} 1.41 \text { to } 2.59 ; \\
P<0.01 \\
\text { Success of stone removal at first } \\
\text { attempt, and procedure duration: } \\
\text { - n.s. }\end{array}$ & $\begin{array}{l}\text { Short-term complications } \\
\text { Overall incidence: } \\
\text { - n.s. } \\
\text { PEP: } \\
\text { - } 9.1 \% \text { vs. } 3.4 \%(P<0.0001) \\
\text { Bleeding: } \\
\text { - } 0.2 \% \text { vs. } 3.4 \%(P<0.01) \\
\text { Infection, perforation and acute } \\
\text { cholangitis: } \\
\text { - n.s. } \\
\text { Long-term complications } \\
\text { Cholecystitis: } \\
\text { - OR } 0.41,95 \% \text { CI } 0.20-0.84 \\
\text { Stone recurrence: } \\
\text { - OR } 0.48,95 \% C I 0.26-0.90\end{array}$ \\
\hline
\end{tabular}

NA, not available; OR, odds ratio; Cl, confidence interval; n.s., not significant; ERCP, endoscopic retrograde cholangiopancreatography; PEP, post-ERCP pancreatitis; EML, endoscopic mechanical lithotripsy.

\subsection{When should balloon dilation be performed?}

Choledocholithiasis is the only indication for EPBD reported in large controlled series [100 - 102], as noted above. EPBD may offer benefits over EST when:

(i) It preserves (at least partly) the function of the sphincter of Oddi, and hence prevents duodenobiliary reflux and bacterial colonization of the bile duct, which may predispose to long-term adverse events including stone recurrence and cholangitis [104];

(ii) It avoids post-EST bleeding, particularly in patients with coagulopathy;

(iii) It facilitates deep biliary access in patients with altered anatomy.

\subsection{Does $\mathrm{CBD}$ diameter influence how the procedure is performed? \\ Summary of the evidence}

In the RCTs of EPBD [105-118], the following anatomical conditions were usually considered as contraindications for EPBD: biliary strictures or ampullary/pancreatic/biliary malignancies; prior biliary surgery except cholecystectomy; acute pancreatitis; precut sphincterotomy for biliary access; and large CBD stones with a cutoff value between 12 and $20 \mathrm{~mm}$, depending on the studies.

It has been suggested that EPBD should be performed using a balloon diameter that is less than that of the CBD, to reduce damage to the sphincter of Oddi and pancreatic orifice [119]. Although this seems logical, no supporting evidence was provided. On the contrary, the incidence of PEP was significantly higher with EPBD than with EST in two out of five studies that used this approach [105-109], while it was not significantly different in both treatment arms in seven of nine studies that used a single balloon diameter for all patients (usually $8 \mathrm{~mm}$, with one study using 10 $\mathrm{mm}$ [110], and another $15 \mathrm{~mm}$ [111]). These results suggest that the balloon size should not be selected on the basis of the diameter of the CBD or stone.

\subsection{Are the success and adverse event rates of balloon dilation and biliary sphincterotomy comparable?}

\subsubsection{Success rates}

\section{Summary of the evidence}

Recent meta-analyses ( 0 Table $\mathbf{6})$ yielded the following results; older meta-analyses $[120,121]$ were disregarded: 
- Liu et al. [101] found that, compared with EST, EPBD yielded similar rates of complete stone removal (94.6\% vs. $95.9 \%$; OR $0.99,95 \% \mathrm{CI} 0.98-1.01$ ), but EPBD required endoscopic mechanical lithotripsy more frequently than EST (35.0\% vs. $26.2 \%$; OR $1.31,95 \%$ CI $1.13-1.51$ ).

- Zhao et al. [102] showed that, compared with EST, EPBD yielded fewer complete stone removals ( $92.4 \%$ vs. $95.1 \%$; OR 0.64 , $95 \% \mathrm{Cl} 0.42-0.96$ ), and that it was associated with more frequent use of stone extraction baskets (OR 1.91, 95\%CI 1.41 2.59). Use of stone extraction baskets with EPBD was particularly frequent when the diameter of stones was larger than $8 \mathrm{~mm}[114], 10 \mathrm{~mm}[113,116]$, or $12 \mathrm{~mm}[115]$.

The small differences between these meta-analyses may be related to the facts that Liu et al. [101] selected RCTs from the last decade only, and also considered that stone clearance was complete in all patients treated with EPBD by Arnold et al. [112] although in that study complete clearance was obtained in 7 of 30 patients (23\%) of the EPBD arm only after shifting to EST.

The overall success rates included performance of rescue EST for patients randomized to EPBD, a factor that was not assessed in these two meta-analyses. An older meta-analysis reported initial success of CBD stone clearance (without use of rescue EST) in $70.0 \%$ vs. $79.8 \%$ with EPBD and EST $(P=0.001)$ [120]. Three recent RCTs that compared EPBD vs. EST in small series and were not included in the meta-analyses showed similar efficacy and safety between the two treatments $[107,108,111]$ ( $\bullet$ Table 7$)$.

\subsubsection{Adverse event rates}

\section{Summary of the evidence}

Short and long-term adverse events were analyzed.

Short-term morbidity. The two meta-analyses cited above [101, 102 ] found no significant difference in overall rates when EPBD and EST were compared ( $\bullet$ Table 6 ) [101, 102]. Both meta-analyses showed more frequent PEP and less frequent bleeding with EPBD vs. EST.
A third meta-analysis [100] analyzed separately RCTs that used balloon dilation of $\leq 1$ minute duration or $>1$ minute duration ( 4 studies and 7 studies, respectively). Compared with EST, short EPBD presented a trend toward a higher overall adverse event rate (OR 1.71, 95\%CI 0.67-4.35) while long EPBD presented a trend toward a lower rate (OR $0.61,95 \% \mathrm{CI} 0.36-1.04)$. With respect to PEP, short EPBD duration was associated with a higher PEP incidence compared with EST (OR 3.87, 95\%CI 1.08-13.84) while long EPBD was not (OR 1.14, 95\%CI 0.56-2.35). In this study a network meta-analysis was also performed that also included an RCT [103] comparing short vs. long EPBD (170 patients). The probabilities of treatment being associated with the lowest incidence of PEP were: long EPBD 43.9\%, short EPBD 0.2 $\%$, and EST $55.9 \%$. The probabilities of treatment being associated with the lowest incidence of overall adverse events were: long EPBD 90.3\%, short EPBD 1.3\%, and EST 8.4\%. The superiority of long EPBD when compared to EST arose from lower bleeding rates in the context of similar PEP rates.

The hypothesized mechanism behind a higher incidence of PEP following short EPBD is that hemorrhage, inflammation and edema develop at the ampulla [122] and an inadequately loosened sphincter from short-duration EPBD may limit volume expansion of its encircled contents causing a compartment syndrome [103]. The single RCT that compared EPBD for 5 minutes vs. EPBD for 1 minute showed better results with 5-minute EPBD in terms both of successful stone extraction with EPBD alone ( $92.9 \%$ vs. $80.2 \%$, respectively; $P=0.024$ ) and PEP (4.8\% vs. $15.1 \%$, respectively; $P=$ 0.038 ) [103]. It also showed a trend towards shorter procedure duration with 5-minute vs. 1-minute EPBD, related to less frequent use of rescue EST or mechanical lithotripsy.

Long-term morbidity. This was assessed in a single meta-analysis (6 RCTs) [102]. Compared to EST, EPBD was associated with lower overall long-term morbidity (OR $0.53,95 \% \mathrm{CI} 0.36-0.77$ ) and a lower incidence of acute cholecystitis (OR $0.41,95 \%$ CI $0.20-$ 0.84 ). The meta-analysis of the three RCTs that had reported biliary stone recurrence showed fewer recurrences with EPBD com-

Table 7 Recent randomized controlled trials (RCTs) that were not included in the most recent meta-analyses, comparing endoscopic papillary balloon dilation (EPBD) vs. endoscopic sphincterotomy (EST) for extracting common bile duct (CBD) stones.

\begin{tabular}{|c|c|c|c|c|c|}
\hline \multirow{2}{*}{$\begin{array}{l}\text { First author } \\
\text { Year [ref.] }\end{array}$} & \multirow[t]{2}{*}{ Population } & \multirow[t]{2}{*}{ Patients, n } & \multirow[t]{2}{*}{ Interventions } & \multicolumn{2}{|l|}{ Outcomes } \\
\hline & & & & Success rates & Complications \\
\hline $\begin{array}{l}\text { Oh } \\
2012 \text { [108] }\end{array}$ & $\begin{array}{l}>45 \text { years } \\
\text { CBD stones }>1 \mathrm{~cm}\end{array}$ & $\begin{array}{l}83 \\
-40 \text { vs. } 43\end{array}$ & $\begin{array}{l}\text { EPBD vs. EST } \\
\text { (Balloon } \\
10-18 \mathrm{~mm} \text { ) }\end{array}$ & $\begin{array}{l}\text { Overall success: } \\
\text { - } 97.5 \% \text { vs. } 95.3 \% \text { (n.s.) } \\
\text { Complete stone removal in one } \\
\text { session: } \\
-82.5 \% \text { vs. } 81.4 \% \text { (n.s.) } \\
\text { EML: } \\
-10 \% \text { vs. } 21 \% \text { (n.s.) }\end{array}$ & $\begin{array}{l}\text { PEP: } \\
\text { - } 5 \% \text { vs. } 7 \% \text { (n.s.) } \\
\text { Bleeding: } \\
\text { - } 10 \% \text { vs. } 16.3 \% \text { (n.s.) } \\
\text { Perforation: } \\
-2.5 \% \text { vs. } 0 \% \text { (n.s.) } \\
\text { Cholangitis: } \\
-5 \% \text { vs. } 2.3 \% \text { (n.s.) }\end{array}$ \\
\hline $\begin{array}{l}\text { Minakari } \\
2013 \text { [111] }\end{array}$ & $\begin{array}{l}\text { CBD stones } \\
10-20 \mathrm{~mm}\end{array}$ & $\begin{array}{l}160 \\
-80 \text { vs. } 80\end{array}$ & $\begin{array}{l}\text { EPBD vs. EST } \\
\text { (Balloon } 15 \mathrm{~mm} \text { ) }\end{array}$ & $\begin{array}{l}\text { Complete stone removal: } \\
\text { - } 97.5 \% \text { vs. } 96.2 \% \text { (n.s.) } \\
\text { EML: } \\
\text { - } 1.3 \% \text { vs. } 1.3 \% \text { (n.s.) }\end{array}$ & $\begin{array}{l}\text { PEP: } \\
-11.2 \% \text { vs. } 8.7 \% \text { (n.s.) } \\
\text { Bleeding: } \\
-1.2 \% \text { vs. } 1.2 \% \text { (n.s.) } \\
\text { Perforation: } \\
-2.5 \% \text { vs. } 0 \% \text { (n.s.) }\end{array}$ \\
\hline $\begin{array}{l}\text { Seo } \\
2014 \text { [107] }\end{array}$ & $\begin{array}{l}<40 \text { years } \\
\text { CBD and } \\
\text { gallbladder stones } \\
\text { (CBD stones } \\
<12 \mathrm{~mm} \text { ) }\end{array}$ & $\begin{array}{l}132 \\
-62 \text { vs. } 70\end{array}$ & $\begin{array}{l}\text { EPBD vs. EST } \\
\text { (Balloon } \\
6-10 \mathrm{~mm} \text { ) }\end{array}$ & $\begin{array}{l}\text { CBD clearance: } \\
\text { - } 98.4 \% \text { vs. } 100 \% \text { (n.s.) } \\
\text { Complete stone removal at one session: } \\
\text { - } 91.9 \% \text { vs. } 91.4 \% \text { (n.s.) } \\
\text { EML: } \\
-8.1 \% \text { vs. } 8.6 \% \text { (n.s.) }\end{array}$ & $\begin{array}{l}\text { Early complications: } \\
\text { - } 8.1 \% \text { vs. } 11.4 \% \text { (5 PEP vs. } 5 \text { PEP, } 1 \\
\quad \text { bleed, } 1 \text { perforation) (n.s.) } \\
\text { CBD recurrence (mean follow-up, } \\
35 \text { months): } \\
-1.6 \% \text { vs. } 5.7 \% \text { (n.s.) }\end{array}$ \\
\hline
\end{tabular}

n.s., nonsignificant; ERCP, endoscopic retrograde cholangiopancreatography; PEP, post-ERCP pancreatitis; EML, endoscopic mechanical lithotripsy 
pared with EST (6.6\% vs. $12.7 \%$; OR $0.48,95 \% \mathrm{CI} ; 0.26-0.90$ ) [102].

Another RCT that was not included in the above meta-analysis also reported that, in 474 patients with biliary stones $\leq 8 \mathrm{~mm}$, overall late adverse events and stone recurrence were less frequent after EPBD than after EST (5.3\% vs. $17.3 \%, P=0.009 ; 4.4 \%$ vs. $12.7 \% ; P=0.048$; respectively) (mean follow-up, 55 months). For larger stones, a statistically significant difference was not observed. [123]. A retrospective cohort study with a median followup of 92 months also showed a lower incidence of CBD stone recurrence after EPBD vs. EST [124].

\subsection{Does routine pancreatic stenting after \\ balloon dilation reduce the risk of pancreatitis? \\ Summary of the evidence}

Routine rectal administration of $100 \mathrm{mg}$ diclofenac or indomethacin immediately before or after ERCP is recommended for PEP prophylaxis in all patients without contraindication because of the strong supporting evidence [7]. NSAIDs alone were shown to be more effective than prophylactic pancreatic stenting alone in a network meta-analysis [125].

In addition to NSAIDs, placement of a 5-Fr prophylactic pancreatic stent should be strongly considered following EPBD as this procedure was considered to represent a high risk for PEP in the ESGE Guideline [7]. However, the following should be considered: (i) the new evidence showing similar PEP incidence with long-duration EPBD compared with EST, (ii) the potential use of EPBD as a routine replacement for EST by endoscopists with limited experience in prophylactic pancreatic stenting, and (iii) the high risk of PEP following failed attempts at prophylactic pancreatic stenting. In view of these points, it is proposed that prophylactic pancreatic stenting should be attempted by endoscopists with experience in this technique and that other endoscopists do not attempt prophylactic pancreatic stenting routinely following long-duration EPBD. The one study that has reported on this area found no statistically significant difference between patients who had received prophylactic pancreatic stenting and those that had not (with a $P$ value of 0.11 reported in the results and a calculated $P$ value of 0.18 when the ESGE Guideline authors subjected the data to a two-tailed Fisher exact test). It should also be noted that the results of the paper did not report on the outcome of the 2 patients in whom pancreatic stent insertion had failed (out of 40) [126].

\section{Pancreatic sphincterotomy}

ESGE does not recommend routine biliary sphincterotomy for patients undergoing pancreatic sphincterotomy, and suggests that it is reserved for patients in whom there is evidence of coexisting bile duct obstruction or biliary sphincter of Oddi dysfunction (moderate quality evidence, weak recommendation).

Pancreatic sphincterotomy has been advocated for selected cases of chronic pancreatitis and SOD [127-130]. Typically a guidewire is sited in the main pancreatic duct to facilitate a pull-type sphincterotomy. Though the position of the cut differs from that of biliary sphincterotomy (1-2-o'clock position vs. 11-1o'clock) many of the technical considerations described in preceding sections remain relevant. An alternative approach is to cut using a needle-knife that is advanced over the top of a pancreatic stent, which is sited prior to the intervention [129]. It should not be confused with papillotomy of the minor papilla which is discussed further in section 10 .

\section{Summary of the evidence}

The role of pancreatic sphincterotomy is less well defined than that of biliary sphincterotomy and a recent randomized clinical trial has challenged the hypothesis that sphincterotomy reduces disability due to pain in post-cholecystectomy patients with suspected SOD [131]. In the context of chronic pancreatitis it is often performed as a precursor to other pancreatic endotherapy and the following discussion addresses the question as to whether a pancreatic sphincterotomy should also be combined with biliary sphincterotomy (dual sphincterotomy).

Biliary sphincterotomy as a precursor to pancreatic sphincterotomy has been suggested as a way to improve visualization of the relevant anatomy prior to pancreatic sphincterotomy [132]. However there are no data to support the hypothesis that biliary sphincterotomy makes pancreatic sphincterotomy technically easier to perform. More importantly it has also been suggested that dual sphincterotomy reduces the risk of adverse events, and in particular cholangitis [133].

\subsection{When the therapeutic intention is pancreatic sphincterotomy, should a biliary sphincterotomy be performed first?}

There is only one randomized study, conducted in the $1990 \mathrm{~s}$, that directly addresses this issue [134]. Patients undergoing endoscopic treatment for non-alcohol-related chronic pancreatitis were allocated to receive either pancreatic sphincterotomy without biliary sphincterotomy or dual sphincterotomy. Patients within each group were defined as having evidence of partial bile duct obstruction if common bile duct diameter was $>12 \mathrm{~mm}$ in combination with an alkaline phosphatase $>2$ times the upper limit of normal. Cholangitis was observed in 5/9 patients who had evidence of partial bile duct obstruction and did not receive biliary sphincterotomy, as opposed to $1 / 51$ patients who made up the remaining subgroups within the study. Whilst this study has not been reproduced elsewhere, findings are consistent with several larger case series of endotherapy for chronic pancreatitis, in which the incidence of cholangitis was low despite the fact that the majority of individuals underwent pancreatic sphincterotomy without biliary sphincterotomy [135]. Therefore for patients in whom there is no biliary obstruction, dual sphincterotomy is unlikely to reduce the risk of an adverse event when compared with pancreatic sphincterotomy alone.

\section{Cannulation and periampullary diverticulum} $\nabla$

In patients with periampullary diverticulum (PAD) and difficult cannulation, ESGE suggests that pancreatic duct stent placement followed by precut sphincterotomy or needle-knife fistulotomy are suitable options to achieve cannulation, and that the most suitable technique should be selected on the basis of patient anatomy and operator experience (low quality evidence, weak recommendation).

ESGE suggests that EST is safe in patients with PAD. In cases where EST is technically difficult to complete as a result of a PAD, large stone removal can be facilitated by a small EST combined with EPBD or use of EPBD alone (low quality evidence, weak recommendation). 
Periampullary diverticulum (PAD) was first reported by Chomel in 1710. In 2006 Boix et al. proposed a classification of PAD, differentiating three types: type I, papilla located inside of the diverticulum (50\%); type II, papilla located in the margin of the diverticulum (30\%); and type III, papilla located close to the diverticulum (20\%) [136]. The overall incidence of PAD varies widely from $6 \%$ to $31.7 \%$ based on different diagnostic approaches $[136,137]$. PADincidence strongly increases with age; PAD is hardly seen in patients aged under 40 .

\subsection{What techniques are available to cannulate the papilla in the presence of a PAD? \\ Summary of the evidence}

A recent literature review by Cappell et al. reveals several different techniques to cannulate the papilla in the presence of a PAD [138]. There are however neither comparative nor prospective studies, all data coming from retrospective or case studies or case reports. The most frequently described techniques in this review are pancreatic duct stent placement followed by precut sphincterotomy [139], needle-knife fistulotomy [140], or cap-assisted forward viewing endoscopy [141]. When the first technique is applied the papilla is kept out of the PADby the placement of a pancreatic duct stent and then a precut is done over the stent; this approach revealed a success rate for CBD cannulation in 7 out of 8 patients (87.5\%) [139]. The drawback of this technique is the prerequisite of deep pancreatic duct cannulation and the PEP risk, which was reported to be as high as $25 \%$ in this series.

The retrospective study by Park et al. on needle-knife fistulotomy compared the efficacy and safety of this technique between patients with and without PAD[140]. The technique was applied in cases of difficult cannulation. Successful cannulation was achieved in 31 out of 33 patients (93.9\%) with PADand in 107 out of 121 patients (88.4\%) without PAD, with no difference in adverse events.

A retrospective study reported that the cap-assisted technique with a forward-viewing endoscope was applied after cannulation with a side-viewing endoscope had failed, and could include an attempt at fistulotomy with a needle-knife [141]. Selective cannulation was achieved in all patients with this technique, either without fistulotomy $(n=4)$ or with additional fistulotomy $(n=8)$. In addition there are case reports on endoclip-assisted cannulation, on a two-devices-in-one-channel method, and on the use of (ultrathin) gastroscopes and echoendoscopes for a rendezvous technique [138].

In conclusion, different techniques are described in the literature regarding cannulation of the papilla in the presence of a PAD, but there is no consensus about the preferred technique.

\subsection{When should balloon dilation be preferred to biliary sphincterotomy in patients with PAD? Summary of the evidence}

There are no specific comparative data indicating when either an EST or EPBD is preferable in patients with PAD. Data on the safety and success rate of EST in patients with PADare sparse. A prospective series, with 227 patients with PADand 447 without, revealed that EST was equally safe (morbidity $5.2 \%$ vs. $4.0 \%$, mortality $0.9 \%$ vs. $0.7 \%$ ) but the overall success rate of EST was significantly lower ( $95.2 \%$ vs. $98.0 \%, P<0.05$ ) [142]. There is another study, primarily focusing on bile duct stone removal, which revealed no difference between the PAD group $(n=83)$ and the case-matched controls $(n=261)$ for adverse events ( $5 \%$ vs. $3.3 \%$, respectively) and an equal success rate of EST (96\% vs. 98\%, respectively) [143].

Liao et al. described four conditions which either on their own or in combination might make an EST difficult: (i) appropriate route for cutting being deviated away from the normal 11-12-o'clock direction; (ii) appropriate route for cutting could not be confidently decided; (iii) control of sphincterotome along the appropriate route was difficult; and (iv) little margin for cutting [144]. In their retrospective study they investigated whether, in cases with these conditions, an EPBD might be more effective and cause fewer complications [144]. They compared two cohorts of patients with PAD who, prior to lithotripsy at their center, received either an EST (patients presenting till 2005) or EPBD with a $10-\mathrm{mm}$ balloon (patients presenting after 2005). The baseline characteristics of the groups were the same, but the complete stone removal rate was 35/35 EPBD patients versus 21/25 EST patients, revealing a significant difference in favor of EPBD. Adverse events occurred in 2 EPBD and 5 EST patients $(P=0.026)$. They concluded that EPBD should be considered in cases where EST is judged to be difficult.

Further studies on EPBD in patients with PAD do specifically focus on removal of larger $(>10 \mathrm{~mm})$ biliary stones that are difficult to remove with conventional methods $[145,146]$. The first retrospective series investigated safety and efficacy of large stone removal in patients with $\operatorname{PAD}(n=73)$ or without $\operatorname{PAD}(n=66)$. EPBD was done with a large balloon (diameter $\geq 10 \mathrm{~mm}$ ) after a small EST [145]. The baseline characteristics were the same with the exception of age: patients with PAD were significantly older. The authors found a rate of stone removal of 69/73 (94.5\%) in the PAD group vs. 62/66 (93.9\%) in controls and no significant difference in overall complications, which amounted to $7 / 73$ (9.6\%) vs. 3/66 (4.5\%), respectively. The other published series reviewed the records of 233 patients with large bile duct stones who underwent EPBD with a $12-20 \mathrm{~mm}$ diameter balloon, with or without limited EST [146]. In this series also, the patients with PAD were significantly older. Stone removal was equally effective (96\% versus $96 \%$ ) and the rates of post-ERCP pancreatitis, perforation, and bleeding were not significantly different between the PADand non-PAD groups. Adverse events within the PADgroup did not differ when EPBD with EST was compared to EPBD without EST. The available data from retrospective series suggest EPBD is an alternative in cases of PAD where EST fails or cannot be applied.

\subsection{What is the impact of a PAD on the technical success and complications of ERCP? \\ Summary of the evidence}

Reviewing the data on the influence of PAD on technical success, as reflected by cannulation rate, reveals a difference between older and more recent literature. The first retrospective study on this topic, published in 1980 and including 755 patients of whom 38 had PAD, showed a large difference regarding failed cannulation rate: $40 \%$ in patients with PADvs. $20 \%$ in the remainder [147]. A prospective study published 7 years later, of 1243 patients who underwent an ERCP, revealed 153 patients with a PAD and a failure rate equal to that in patients without $\operatorname{PAD}(8.49$ $\%$ vs. $8.99 \%$ ) [148]. However in 1989 a large prospectively reported series of 2458 patients including 308 with PAD revealed a cannulation rate of $94.2 \%$ (with PAD) vs. 96.7\% (no PAD), which appeared to be significantly different [142].

The more recent data, consisting of several prospective studies, are more coherent. Four out of six studies revealed no significant difference with regard to technical success between patients with 
and without PAD [136, 143,149,150]; one study only mentioned the high success rate in patients with PAD [151]; and another series, including 44 patients with PAD and 736 without, revealed a significant difference, favoring cannulation in patients without PAD [152]. None of these studies corrected for age differences which were significantly higher in five of the six studies [136, 149-152]. This is of interest as, according to Balik et al., for each 1-year increase in age the cannulation failure rate appeared to increase by 1.01 ( $95 \% \mathrm{CI} 1.004-1.016, P=0.002$ ). This analysis, on 5079 patients undergoing ERCP (660 with PAD), investigating parameters that might predict failure, further revealed that PAD did not influence the success rate of cannulation during ERCP [153]. These findings are in accordance with the only other identified full-text available study that takes PADinto consideration as a risk factor for failed cannulation [154].

With regard to safety, none of the six prospective studies revealed any significant difference regarding either overall adverse events or specific types of event including PEP, perforation, and bleeding $[136,143,149-152]$ ( $\bullet$ Table 8$)$. This was confirmed in another large multicenter study including 4561 patients [155], while a multicenter study including 2691 patients identified PAD as a risk factor for overall complications in a multivariate analysis (OR 2.02, 95\%CI $1.49-2.73, P<0.001)[156]$.

\section{Cannulation and sphincterotomy of the minor papilla \\ $\nabla$}

When cannulation of the minor papilla is difficult, ESGE suggests secretin injection, which can be preceded by methylene blue spray in the duodenum (low quality evidence, weak recommendation).

To diagnose pancreas divisum, ESGE suggests using morphological criteria (bulging, opening, and pancreatic fluid secretion) in combination with MRCP, which should always be performed before pancreatic ERCP unless contraindicated (low quality evidence, weak recommendation).

ESGE suggests using wire-guided cannulation, with or without contrast, and sphincterotomy with a pull-type sphincterotome or a needle-knife over a plastic stent, according to the operator's experience and available devices (low quality evidence, weak recommendation).

Pancreas divisum is the most common congenital variant of pancreatic duct anatomy, arising when the embryological ventral and dorsal endodermal buds fail to fuse ("classic" pancreas divi- sum) or only partially fuse ("incomplete" pancreas divisum). With this ductal variant, pancreatic drainage is mainly through the accessory papilla [157].

For more than 150 years, anatomists and later clinicians used different methods to describe pancreas divisum, including autopsy, surgery, ERCP, magnetic resonance pancreatography (MRCP), and secretin-MRCP. A recent comprehensive study, grouping autopsy, MRCP, and ERCP studies, evaluated the prevalence of pancreas divisum in the general population, as well as in patients with idiopathic recurrent acute or chronic pancreatitis. The authors determined a prevalence of $8 \%$ in the general population based on autopsy and MRCP studies, whereas based on ERCP studies, the prevalence was $4 \%$ in the general population compared to $8 \%$ in patients with pancreatitis. These data support the conclusion that prevalence of pancreas divisum in the general population is comparable to that in patients with pancreatitis, and that underrecognition or referral bias could explain the lower prevalence in the general population found in ERCP studies. Consequently, the authors concluded that there is no causative link between pancreas divisum and pancreatitis [158]. Nevertheless, patients with recurrent acute or chronic pancreatitis who have complete or incomplete pancreas divisum, may still be recommended to have endoscopic therapy and dorsal pancreatic duct drainage by minor papilla sphincterotomy.

\subsection{Which techniques can be helpful in cases of difficult identification of the minor papilla? \\ Summary of the evidence}

The minor papilla is usually identified 15 to $20 \mathrm{~mm}$ above the major papilla in the 1-2-o'clock direction when viewed using a duodenoscope. It is smaller than the major papilla and lacks a longitudinal fold. In some patients with pancreas divisum, minor papilla cannulation is difficult because of uncertain identification of the papilla or the absence of a visible opening.

Identification of the minor papilla orifice may be facilitated by increasing the production of pancreatic juice, which results in a visible flow of juice into the duodenum. Moreover, when pancreatic juice flow is increased the orifice enlarges, simplifying guidewire or catheter insertion. A multicenter randomized controlled comparative trial including 29 patients showed significantly higher cannulation rates after secretin injection compared with placebo ( $81.3 \%$ vs. $7.7 \%, P<0.01$ ) [159].

Some authors have proposed spraying methylene blue solution onto the mucosa in the region suspected to contain the minor papilla, before secretin injection; this often facilitates identification

\begin{tabular}{|c|c|c|c|}
\hline \multirow{2}{*}{$\begin{array}{l}\text { First author } \\
\text { Year [ref.] }\end{array}$} & \multicolumn{2}{|l|}{ Successful cannulation } & \multirow[t]{2}{*}{$P$ value } \\
\hline & Patients with PAD, \% (n/n) & Patients without PAD, \% (n/n) & \\
\hline $\begin{array}{l}\text { Katsinelos } \\
2013 \text { [149] }\end{array}$ & $92.2 \%(104 / 107)$ & $99.7 \%(320 / 321)$ & 0.05 \\
\hline $\begin{array}{l}\text { Alizadeh } \\
2013 \text { [152] }\end{array}$ & $64.5 \%$ & $88.5 \%$ & $<0.001$ \\
\hline $\begin{array}{l}\text { Tyagi } \\
2009 \text { [151] }\end{array}$ & $97 \%(45 / 46)$ & NA & - \\
\hline $\begin{array}{l}\text { Panteris } \\
2008 \text { [150] }\end{array}$ & $94.9 \%(111 / 117)$ & $94.8 \%(459 / 484)$ & n.s. \\
\hline $\begin{array}{l}\text { Boix } \\
2006 \text { [136] }\end{array}$ & $91.1 \%(118 / 131)$ & $88.1 \%(237 / 269)$ & n.s. \\
\hline $\begin{array}{l}\text { Tham } \\
2004 \text { [143] }\end{array}$ & $94 \%(78 / 93)$ & $94 \%(245 / 261)$ & n.s. \\
\hline
\end{tabular}

Table 8 Prospective studies evaluating cannulation success rate in presence and absence of periampullary diverticulum (PAD)

NA, not available; n.s, not significant. 
of the papilla or its orifice [160]. Another technique is injection of a mixture of contrast media and methylene blue through the major papilla and the ventral duct [160] in cases of incomplete pancreas divisum. A retrospective series involving 38/305 patients with pancreas divisum, in whom cannulation by conventional means was unsuccessful, described 14 patients in whom the minor papilla orifice remained inconspicuous despite secretin injection. By using the methylene blue spraying or injection technique, the minor papilla was successfully identified and cannulated in 12 of these patients [160].

However, secretin is expensive and not always readily available. An alternative described in a small randomized controlled trial including 12 patients showed that duodenal acid infusion $(45 \mathrm{~mL}$ of $0.1 \mathrm{~mol} \mathrm{HCl})$ facilitated minor papilla cannulation when compared to placebo ( $73 \%$ vs. $13 \%, P=0.02)$ [161].

\subsection{Does minor papilla morphology predict pancreas divisum?}

\section{Summary of the evidence}

Two prospective studies assessed whether simple inspection of the minor papilla during initial duodenal entry during ERCP can predict the presence of pancreas divisum $[162,163]$. The probability of pancreas divisum based on the appearance of the minor papilla was estimated by assessing the size of the minor papilla, the diameter of the orifice, and whether juice was seen draining through the orifice. The appearance of the minor papilla has a positive predictive value of $57.5 \%$ and a negative predictive value of $88.9 \%$ in detecting pancreas divisum [162]. A scoring system that graded bulging and orifice opening revealed higher scores in patients with pancreas divisum [163]. In some cases associated with a santorinicele (which can usually be demonstrated by dynamic MRCP), the injection of secretin induces a bulging of the duodenal mucosa above the orifice of the accessory papilla [164].

\subsection{What sphincterotomy techniques can be used at} the minor papilla and do they differ in performance?

\section{Summary of the evidence}

Cannulation of the minor papilla may be challenging, and historically experts have often advocated the use of specialized accessories (e.g., needle-tip catheters, ultratapered tip catheters) and small-caliber guidewires (e.g., 0.018 -inch or 0.021-inch) when approaching the minor papilla.

Recent reviews on technical options for pancreatic sphincterotomy of the minor papilla include a standard pull-type cut with a 4.4-Fr sphincterotome and a needle-knife cut over a plastic stent $[165,166]$. A retrospective, comparative study $(n=184)$ concluded that both techniques were equally safe and effective. Overall adverse event rates were similar in those undergoing needleknife and pull-type sphincterotome ( $8.3 \%$ vs. $7.8 \%$, respectively). Re-intervention rates were similar, with papillary re-stenosis rates of $24 \%$ over a median follow-up of 6 years after needle-knife cut and $20 \%$ over a median follow-up of 5 years after pull-type sphincterotome cut [165].

Another technique, the wire-assisted access sphincterotomy has been described, and is performed by deeply cannulating the dorsal duct with a guidewire, then passing a needle-knife sphincterotome alongside the wire and cutting the minor papilla by cutting away from the wire. A retrospective study comparing the above technique with the pull-type sphincterotome revealed similar rates of adverse events [166].
Finally, minor papilla sphincteroplasty with balloon dilation has been shown to be safe and efficient in a small retrospective study [167].

\section{Anterograde guidewire-assisted biliary cannulation \\ $\nabla$}

\begin{abstract}
In patients with choledocholithiasis who are scheduled for elective cholecystectomy, ESGE suggests intraoperative ERCP with laparoendoscopic rendezvous where local expertise and conditions allow (moderate quality evidence, weak recommendation
\end{abstract}

ESGE suggests that when biliary cannulation is unsuccessful with a standard retrograde approach, anterograde guidewire insertion either by a percutaneous or EUS-guided approach can be used to achieve biliary access. Which approach is utilized will depend on local expertise and facilities (low quality evidence, weak recommendation).

Cannulation of the biliary or pancreatic ducts may be facilitated by means of a rendezvous technique. This technique assists biliary cannulation by passing a wire in an anterograde direction through the papilla and into the duodenum. Several related methods have been described: a surgical approach, the percutaneous route, and endoscopic ultrasound-guided anterograde cannulation.

Removal of the gallbladder in combination with CBD stone extraction may be managed in two steps (ERCP prior to or after surgical cholecystectomy), or as a one-step combined procedure consisting of laparoscopic duct exploration or intraoperative ERCP immediately after laparoscopic cholecystectomy. The former technique is beyond the remit of this guidance. Intraoperative ERCP has been performed using the standard retrograde approach or a laparoendoscopic rendezvous technique, where a guidewire is introduced into the duodenum through the cystic duct to facilitate retrograde cannulation.

In cases of failed ERCP, patients are classically referred for treatment via the percutaneous or the surgical rescue approach. Two percutaneous biliary procedures may be performed in this situation: using a rendezvous technique or anterograde percutaneous transhepatic biliary drainage (PTBD). More recently, three variants of endoscopic ultrasound-guided biliary drainage (EUS-BD) have been described: rendezvous or anterograde stenting guided by endoscopic ultrasound, with a third technique that involves direct transluminal stenting through the gastric, duodenal, or jejunal wall. This approach has theoretical advantages, in that it can be performed even when passage of a wire through a biliary stricture cannot even be attempted.

\subsection{Are there differences in the success and safety} of intraoperative and preoperative endoscopic biliary sphincterotomy?

\section{Summary of the evidence}

The technical success of intraoperative endoscopic sphincterotomy (IOES) ranges from $90 \%$ to $100 \%[168,169]$ ( $\bullet$ Table 9 [170-174]). One meta-analysis including 5 RCTs and 631 patients compared IOES and preoperative endoscopic sphincterotomy (PES) followed by laparoscopic cholecystectomy (175). It found a higher failure rate for CBD cannulation in PES vs. IOES patients (RR 2.54, 95\%CI 1.23-5.26; $P=0.01$ ) but no significant difference in overall CBD stone clearance rates [170-175]. Duration 


\begin{tabular}{|c|c|c|c|c|c|c|c|c|}
\hline $\begin{array}{l}\text { First } \\
\text { author } \\
\text { Year [ref] }\end{array}$ & $\begin{array}{l}\text { Study design } \\
\text { Quality }\end{array}$ & Intervention & $\begin{array}{l}\text { Patients, } \\
\text { n }\end{array}$ & $\begin{array}{l}\text { Cannulation success, } \\
\%\end{array}$ & $\begin{array}{l}\text { Clearance of } \\
\text { common } \\
\text { bile duct, \% }\end{array}$ & $\begin{array}{l}\text { Overall } \\
\text { morbidity, } \\
\%\end{array}$ & $\begin{array}{l}\text { ERCP- } \\
\text { related } \\
\text { morbidity, } \\
\%\end{array}$ & $\begin{array}{l}\text { Clinical } \\
\text { pancreatitis, } \\
\%\end{array}$ \\
\hline \multirow[t]{2}{*}{$\begin{array}{l}\text { ElGeidi } \\
2011 \text { [174] }\end{array}$} & \multirow{2}{*}{$\begin{array}{l}\text { RCTs } \\
\text { High quality } \\
\text { evidence }\end{array}$} & $\begin{array}{l}\text { PES / Laparoscopic } \\
\text { cholecystectomy }\end{array}$ & 100 & 97 & 97.8 & 3 & 3 & 0 \\
\hline & & $\begin{array}{l}\text { Laparoscopic chole- } \\
\text { cystectomy / IOES }\end{array}$ & 98 & 98 & 95.3 & 4.5 & 3 & 0 \\
\hline \multirow[t]{2}{*}{$\begin{array}{l}\text { Morino } \\
2006[172]\end{array}$} & \multirow{2}{*}{$\begin{array}{l}\text { RCTs } \\
\text { High quality } \\
\text { evidence }\end{array}$} & $\begin{array}{l}\text { PES / Laparoscopic } \\
\text { cholecystectomy }\end{array}$ & 45 & 84.4 & 80 & 8.8 & 6.6 & 0 \\
\hline & & $\begin{array}{l}\text { Laparoscopic } \\
\text { cholecystectomy/ } \\
\text { laparoendoscopic } \\
\text { rendezvous }\end{array}$ & 46 & 97.8 & 95.6 & 6.5 & 2.1 & 0 \\
\hline \multirow[t]{2}{*}{$\begin{array}{l}\text { Rábago } \\
2006 \text { [173] }\end{array}$} & \multirow{2}{*}{$\begin{array}{l}\text { RCTs } \\
\text { High quality } \\
\text { evidence }\end{array}$} & $\begin{array}{l}\text { PES / Laparoscopic } \\
\text { cholecystectomy }\end{array}$ & 64 & 96.9 & 96.9 & 23 & 18.8 & 12.7 \\
\hline & & $\begin{array}{l}\text { Laparoscopic } \\
\text { cholecystectomy/ } \\
\text { Laparoendoscopic } \\
\text { rendezvous }\end{array}$ & 59 & 91.5 & 88.1 & 8.5 & 5.1 & 1.7 \\
\hline \multirow[t]{2}{*}{$\begin{array}{l}\text { Tzovaras } \\
2012 \text { [171] }\end{array}$} & \multirow{2}{*}{$\begin{array}{l}\text { RCTs } \\
\text { High quality } \\
\text { evidence }\end{array}$} & $\begin{array}{l}\text { PES / laparoscopic } \\
\text { cholecystectomy }\end{array}$ & 49 & 90 & 90 & 12 & $\begin{array}{l}\text { Not } \\
\text { reported }\end{array}$ & 0 \\
\hline & & $\begin{array}{l}\text { Laparoscopic } \\
\text { cholecystectomy/ } \\
\text { Laparoendoscopic } \\
\text { rendezvous }\end{array}$ & 50 & $\begin{array}{l}100 \\
\text { Failure of rendezvous } \\
\text { technique, } 6(12 \%)\end{array}$ & 94 & 14 & $\begin{array}{l}\text { Not } \\
\text { reported }\end{array}$ & 0 \\
\hline \multirow[t]{2}{*}{$\begin{array}{l}\text { Lella } \\
2006[170]\end{array}$} & \multirow{2}{*}{$\begin{array}{l}\text { RCTs } \\
\text { High quality } \\
\text { evidence }\end{array}$} & $\begin{array}{l}\text { PES / Laparoscopic } \\
\text { cholecystectomy }\end{array}$ & 60 & 100 & 100 & 8 & 8 & 6 \\
\hline & & $\begin{array}{l}\text { Laparoscopic } \\
\text { cholecystectomy/ } \\
\text { Laparoendoscopic } \\
\text { rendezvous }\end{array}$ & 59 & $\begin{array}{l}100 \\
\text { Failure of rendezvous } \\
\text { technique, } 1(1.7 \%)\end{array}$ & 96 & 2 & 2 & 0 \\
\hline
\end{tabular}

RCT, randomized controlled trial; ERCP, endoscopic retrograde cholangiopancreatography; PES, preoperative endoscopic sphincterotomy; IOES: intraoperative endoscopic sphincterotomy.

of hospital stay was significantly reduced in the IOES group. Overall adverse events, surgical complications, and conversion to open operation were similar in both groups. However, ERCPrelated morbidity was higher in the PES group than in the IOES group (RR 2.27, 95\%CI 1.18-4.40; $P=0.01$ ). In particular, hyperamylasemia (RR 1.90, 95\%CI 1.60 - 6.16) and acute pancreatitis (RR 4.8, 95\%CI 1.41-16.66) occurred more frequently after PES. It should be noted that one RCT included in the pooled analysis evaluated both techniques in patients with one or more risk factors for PEP, and observed a reduction of the risk of PEP in the laparoendoscopic rendezvous group. When this study (that included only high risk patients) is excluded, there is no significant difference between the two groups concerning the risk of PEP (RR $3.24,95 \%$ CI $0.79-13.28 ; P=0.10)$.

Three other meta-analyses confirm the superiority of IOES over the two-step approach, in term of success, adverse events rate, and length of hospital stay [176-178]. The lower PEP rate reported with IOES compared with PES may be related to the use of a transcystic guidewire that drastically reduces manipulation of the papilla. However, routine intraoperative ERCP may be difficult to put into practice because of local constraints in terms of personnel, material, and organization.
11.2 Are there differences in the efficacy and safety of endosonography-guided and percutaneous biliary drainage when used for patients with a papilla that is inaccessible at ERCP?

\section{Summary of the evidence}

The technical success rate of PTBD ranges from $60 \%$ to $90 \%$ and the morbidity rate ranges from $18 \%$ to $67 \%$ [179]. Inability to pass a biliary stricture may necessitate temporary or permanent external drainage which can impair the patient's quality of life. Re-interventions for patients with internal drainage may also require further percutaneous access. The technical success rate of EUS-BD ranges from $70 \%$ to $100 \%$ and the morbidity rate ranges from $3 \%$ to $77 \%$ [180]. A multicentric retrospective study reported no significant difference between the intrahepatic and extrahepatic approaches for technical success (84.3\% vs. $90.4 \%$; $P=$ 0.15 ) or morbidity (32.6\% vs. $35.6 \% ; P=0.64$ ) [181].

Very few comparative studies are available. An RCT comparing PTBD and EUS-BD in 25 patients [182] has shown similar technical and clinical success rates in both groups (100\%). Morbidity rates for PTBD and EUS-BD were $25 \%$ and $15 \%$, respectively $(P=$ $0.2)$. Two comparative studies $[183,184]$ reported conflicting results for either technical or clinical success rates but a higher incidence of complications for PTBD than EUS-BD ( Table 10). Failure of internal stenting ( $8 \%$ vs. 54\%) and need for multiple sessions (0 vs. $19 \%$ ) also favored the EUS-BD group in one study [181]. In a recent multicenter, retrospective study by Dhir et al. [185] that included 208 patients, 104 treated with ERCP and 104 
Table 10 Success rate and complications for percutaneous transhepatic biliary drainage (PTBD) and endoscopic ultrasound-guided biliary drainage (EUS-BD).

\begin{tabular}{|c|c|c|c|c|c|c|}
\hline $\begin{array}{l}\text { First author } \\
\text { Year [ref.] }\end{array}$ & $\begin{array}{l}\text { Study design } \\
\text { Quality }\end{array}$ & Intervention & Patients, n & $\begin{array}{l}\text { Technical success, } \\
\%\end{array}$ & Clinical success, \% & Overall morbidity, \% \\
\hline Artifon & RCT & PTBD & 12 & 100 & 100 & 25 \\
\hline 2012 [182] & $\begin{array}{l}\text { Moderate quality } \\
\text { evidence }\end{array}$ & EUS-BD & 13 & 100 & 100 & 15.3 \\
\hline Bapaye & Retrospective & PTBD & 26 & 46 & NA & 46 \\
\hline 2013 [184] & $\begin{array}{l}\text { comparison } \\
\text { Low quality evidence }\end{array}$ & EUS-BD & 25 & 92 & NA & 20 \\
\hline Khashab & Retrospective & PTBD & 51 & 100 & 92.2 & 39.2 \\
\hline 2015 [183] & $\begin{array}{l}\text { comparison } \\
\text { Low quality evidence }\end{array}$ & EUS-BD & 22 & 86.4 & 86.4 & 18.2 \\
\hline
\end{tabular}

$\mathrm{RCT}$, randomized controlled trial; NA, not available

treated with EUS-BD, biliary drainage was successful in $94.23 \%$ and $93.26 \%$ of patients, respectively $(P=1.00)$. The frequency of adverse events in the ERCP and EUS-BD groups was $8.65 \%$ and $8.65 \%$, respectively. Post-procedure pancreatitis rates were higher in the ERCP group ( $4.8 \%$ vs. $0, P=0.059$ ). The mean procedure times in the ERCP and EUS-BD groups were similar (30.10 and 35.95 minutes, $P=0.05$ ).

\section{Cannulation and sphincterotomy in altered anatomy \\ $\nabla$}

ESGE suggests that in patients with Billroth II gastrectomy ERCP should be performed in referral centers, with the side-viewing endoscope as a first option; forward-viewing endoscopes (gastroscope, pediatric colonoscope, and balloon enteroscope) are the second choice in cases of failure (low quality evidence, weak recommendation).

A straight standard ERCP catheter or an inverted sphincterotome, with or without the guidewire, is recommended by ESGE for biliopancreatic cannulation in patients who have undergone Billroth II gastrectomy (low quality evidence, strong recommendation).

ESGE suggests sphincterotomy in Billroth II gastrectomy patients should be performed with an inverted sphincterotome over the guidewire. Endoscopic papillary balloon dilation (EPBD) is a suggested as an alternative to sphincterotomy for stone extraction in this setting (low quality evidence, weak recommendation).

In patients with complex post-surgical anatomy ESGE suggests referral to a center where device-assisted enteroscopy techniques are available (very low quality evidence, weak recommendation).

ERCP after Billroth II gastrectomy is a challenging procedure with an increased risk of perforation. The first difficulty is entering the afferent loop and reaching the duodenal stump.Cannulation of the papilla and sphincterotomy in a reverse position are the main technical issues that follow from this.

\subsection{What are the different techniques for papillary cannulation and biliary sphincterotomy in patients with Billroth II gastrectomy? \\ Summary of the evidence}

A single RCT [186] by Kim et al. compared forward-viewing vs. side-viewing endoscopes for performing ERCP in Billroth II anatomy in 45 patients. Cannulation and sphincterotomy were successful with the side- and forward-viewing endoscopes in $80 \%$ and $83 \%$ of patients, respectively. The forward-viewing endoscope was more successful in obtaining afferent loop intubation without any perforation, a complication reported in $18 \%$ of the cases with the side-viewing duodenoscope. The absence of perforations when performing ERCP in Billroth II patients with the forward-viewing endoscope was confirmed in another singlearm study [187]. Other series [188-190] described a lower risk of perforation with the duodenoscope in Billroth II anatomy than that reported by Kim et al. [186]. A recent study [191] on 713 ERCPs in Billroth II patients reported a $2.7 \%$ incidence of perforation ( Table11).

Biliopancreatic cannulation and sphincterotomy in Billroth II patients can be facilitated using the side-viewing duodenoscope: it obtains a better visualization of the papilla and the elevator assists in correct orientation of the catheters. For these reasons some experts $[189,191]$ suggest the routine use of a side-viewing duodenoscope for ERCP in Billroth II patients, with use of the forward-viewing endoscopes (gastroscope or pediatric colonoscope) after a failed attempt with the duodenoscope. The direction for biliary cannulation after Billroth II gastrectomy is oriented at 5-o'clock, and straight catheters were commonly used to gain access to the bile duct [186-188,190,191].

Sphincterotomy in Billroth II patients can be performed with a dedicated inverted sphincterotome $[188,189]$ over the guidewire [191], obtaining a controlled incision with a reproducible technique. If this device is not available, another method is the "stent-guided endoscopic sphincterotomy," using a needle-knife sphincterotome [186-188,190,191] after insertion of a 7-Fr biliary stent; this technique makes the "freehand" precut technique more controlled, using the stent to identify the infundibulum in a reverse position. An alternative to sphincterotomy alone is EPBD (with or without a small sphincterotomy), especially for stones $>10 \mathrm{~mm}(192,193)$.

When ERCP is performed in Billroth II patients the success rate increases after the first 50 cases [191]; for that reason it is preferable to refer these cases to tertiary care centers.

Balloon-assisted enteroscopy can increase the success rate of duodenal stump intubation in Billroth II patients [194]. Nevertheless the therapeutic role of ERCP-assisted balloon enteroscopy is limited because of the forward view, the small operative channel, the lack of the elevator, and the absence of ERCP-dedicated catheters [191]. ERCP-assisted balloon-enteroscopy is not therefore routinely used in Billroth II anatomy. 
Table 11 Outcomes of endoscopic retrograde cholangiopancreatography (ERCP) in Billroth Il patients.

\begin{tabular}{|c|c|c|c|c|c|c|}
\hline $\begin{array}{l}\text { First author } \\
\text { Year [ref] } \\
\text { Country }\end{array}$ & $\begin{array}{l}\text { Study } \\
\text { design }\end{array}$ & Intervention & Participants, n & Outcomes & Results & $\begin{array}{l}\text { Level of } \\
\text { evidence }\end{array}$ \\
\hline $\begin{array}{l}\text { Kim } \\
1997[186] \\
\text { Korea }\end{array}$ & RCT & $\begin{array}{l}\text { Side-viewing vs. forward- } \\
\text { viewing endoscope } \\
\text { Cannulation with a straight } \\
\text { catheter } \\
\text { Needle-knife sphincterot- } \\
\text { omy (not over a 7-Fr stent) }\end{array}$ & $\begin{array}{l}45 \text { patients } \\
-22 \text { side-viewing } \\
-23 \text { forward-viewing }\end{array}$ & $\begin{array}{l}\text { Success in: } \\
\text { Afferent loop } \\
\text { intubation } \\
\text { Biliopancreatic } \\
\text { cannulation } \\
\text { Sphincterotomy } \\
\text { Complications }\end{array}$ & $\begin{array}{l}\text { Afferent loop intubation: } \\
\text { - Side-viewing, } 68 \% \\
\text { - Forward-viewing, } 91 \% \\
\text { Biliopancreatic } \\
\text { cannulation: } \\
\text { - Side-viewing, 100\% } \\
\text { - Forward-viewing, 95\% } \\
\text { Sphincterotomy: } \\
\text { - Side-viewing, 80\% } \\
\text { - Forward-viewing, 83\% } \\
\text { Perforation rate: } \\
\text { - Side-viewing, 18\% } \\
\text { - Forward-viewing, 0\%) } \\
\text { Mortality: } \\
\text { - 0\% }\end{array}$ & Moderate \\
\hline $\begin{array}{l}\text { Hintze } \\
1997[189] \\
\text { Germany }\end{array}$ & $\begin{array}{l}\text { Cohort } \\
\text { study }\end{array}$ & $\begin{array}{l}\text { Side-viewing endoscope } \\
\text { S-shaped sphincterotome } \\
\text { for cannulation and sphinc- } \\
\text { terotomy }\end{array}$ & 59 patients & $\begin{array}{l}\text { Success in: } \\
\text { Afferent loop } \\
\text { intubation } \\
\text { Biliopancreatic } \\
\text { cannulation } \\
\text { Sphincterotomy } \\
\text { Complications }\end{array}$ & $\begin{array}{l}\text { Afferent loop intubation: } \\
-92 \% \\
\text { Biliopancreatic } \\
\text { cannulation: } \\
-100 \% \\
\text { Sphincterotomy: } \\
-92 \% \\
\text { Perforation rate: } \\
-2 \% \\
\text { Mortality: } \\
-0 \%\end{array}$ & Low \\
\hline $\begin{array}{l}\text { Aabakken } \\
1998[188] \\
\text { Norway }\end{array}$ & $\begin{array}{l}\text { Cohort } \\
\text { study }\end{array}$ & $\begin{array}{l}\text { Side-viewing } \\
\text { Cannulation with a straight } \\
\text { catheter, or preformed } \\
\text { catheter in case of failure. } \\
\text { Sphincterotomy with a long- } \\
\text { nose papillotome, supra- } \\
\text { papillary fistulotomy, or } \\
\text { needle-knife sphinctero- } \\
\text { tomy over 7-Fr stent }\end{array}$ & 138 patients & $\begin{array}{l}\text { Success in: } \\
\text { Afferent loop } \\
\text { intubation } \\
\text { Biliopancreatic } \\
\text { cannulation } \\
\text { Sphincterotomy } \\
\text { Complications }\end{array}$ & $\begin{array}{l}\text { Afferent loop intubation: } \\
-92 \% \\
\text { Biliopancreatic } \\
\text { cannulation: } \\
-89 \% \\
\text { Sphincterotomy: } \\
-93 \% \\
\text { Perforation rate: } \\
-0.7 \%\end{array}$ & Low \\
\hline $\begin{array}{l}\text { Lin } \\
1999 \text { [187] } \\
\text { Taiwan }\end{array}$ & $\begin{array}{l}\text { Cohort } \\
\text { study }\end{array}$ & $\begin{array}{l}\text { Forward-viewing endoscope } \\
\text { Cannulation with a straight } \\
\text { catheter } \\
\text { Needle-knife sphinctero- } \\
\text { tomy over 7-Fr stent }\end{array}$ & 56 patients & $\begin{array}{l}\text { Success in: } \\
\text { Afferent loop } \\
\text { intubation } \\
\text { Biliopancreatic } \\
\text { cannulation } \\
\text { Sphincterotomy } \\
\text { Complications }\end{array}$ & $\begin{array}{l}\text { Afferent loop intubation: } \\
-76 \% \\
\text { Biliopancreatic } \\
\text { cannulation: } \\
-81 \% \\
\text { Sphincterotomy: } \\
-80 \% \\
\text { Perforation rate: } \\
-0 \\
\text { Mortality: } \\
-0\end{array}$ & Low \\
\hline $\begin{array}{l}\text { Çiçek } \\
2007[190] \\
\text { Turkey }\end{array}$ & $\begin{array}{l}\text { Cohort } \\
\text { study }\end{array}$ & $\begin{array}{l}\text { Side-viewing } \\
\text { Cannulation with a catheter } \\
\text { + guidewire (the tip was } \\
\text { curled upside down) } \\
\text { Needle-knife sphinctero- } \\
\text { tomy over 7-Fr stent }\end{array}$ & 59 patients & $\begin{array}{l}\text { Success in: } \\
\text { Afferent loop } \\
\text { intubation } \\
\text { Biliopancreatic } \\
\text { cannulation } \\
\text { Complications }\end{array}$ & $\begin{array}{l}\text { Afferent loop intubation: } \\
-86 \% \\
\text { Biliopancreatic } \\
\text { cannulation: } \\
-88 \% \\
\text { Perforation rate: } \\
-10 \% \\
\text { Mortality: } \\
-1.7 \%\end{array}$ & Low \\
\hline
\end{tabular}




\begin{tabular}{|c|c|c|c|c|c|c|}
\hline $\begin{array}{l}\text { First author } \\
\text { Year [ref] } \\
\text { Country }\end{array}$ & $\begin{array}{l}\text { Study } \\
\text { design }\end{array}$ & Intervention & Participants, n & Outcomes & Results & $\begin{array}{l}\text { Level of } \\
\text { evidence }\end{array}$ \\
\hline $\begin{array}{l}\text { Bove } \\
2015 \text { [191] } \\
\text { Italy }\end{array}$ & $\begin{array}{l}\text { Cohort } \\
\text { study }\end{array}$ & $\begin{array}{l}\text { Side-viewing } \\
\text { Cannulation with a straight } \\
\text { catheter } \\
\text { Long-nose, inverted sphinc- } \\
\text { terotome (preferred) or } \\
\text { needle-knife sphinctero- } \\
\text { tomy over 7-Fr stent }\end{array}$ & 713 patients & $\begin{array}{l}\text { Success in: } \\
\text { Afferent loop } \\
\text { intubation } \\
\text { Biliopancreatic } \\
\text { cannulation } \\
\text { Sphincterotomy } \\
\text { Complications }\end{array}$ & $\begin{array}{l}\text { Afferent loop intubation: } \\
-88 \% \\
\text { Biliopancreatic } \\
\text { cannulation: } \\
-95 \% \\
\text { All sphincterotomies } \\
\text { were successful, includ- } \\
\text { ing biliary and pancreatic } \\
\text { (major and minor papilla) } \\
\text { Perforation rate: } \\
\text { - } 2.7 \% \\
\text { Mortality: } \\
-0.3 \%\end{array}$ & Low \\
\hline
\end{tabular}

\subsection{Are there different techniques for papilla cannulation in patients with post-surgical anatomy other than Billroth II gastrectomy? \\ Summary of the evidence}

Patients with biliopancreatic diseases and altered anatomy other than by Billroth II gastrectomy present specific endoscopic challenges. The principal groups are patients with intact papillas (gastric resection with Roux-en-Y reconstruction, gastric bypass, and upper duodenal obstruction with palliative gastrojejunostomy), and those with a reconstructed hepatoenteric anastomosis (Roux-en-Y with hepaticojejunostomy, Whipple's duodenopancreatectomy) [195].

Depending on the specific surgery performed, some of these situations may be managed using a standard duodenoscope or a (pediatric) colonoscope, but in most cases, device-assisted enteroscopy is preferable, to simplify intubation and reduce the risk of afferent loop perforations. Cannulation of the intact papilla may be a particular challenge because of the limited navigational capabilities of the looped enteroscope, as well as the limited accessories available for this instrument. A transparent cap may aid intubation as well as papillary manipulation. EPBD for stones extraction can be used in Roux-en-Y anatomy with good results [196]. Hepaticojejunostomies are usually easier to negotiate, although locating stenotic anastomoses may sometimes pose a challenge. These experiences are described in case reports and series from referral centers with availability and experience of balloon enteroscopy techniques [197]. Reported success rates for ERCP procedures are in the range $60 \%-80 \%$, and the need for adapted instruments and accessories is well documented [196].

ESGE guidelines represent a consensus of best practice based on the available evidence at the time of preparation. They may not apply in all situations and should be interpreted in the light of specific clinical situations and resource availability. Further controlled clinical studies may be needed to clarify aspects of these statements, and revision may be necessary as new data appear. Clinical considerations may justify a course of action at variance to these recommendations. ESGE guidelines are intended to be an educational device to provide information that may assist endoscopists in providing care to patients. They are not rules and should not be construed as establishing a legal standard of care or as encouraging, advocating, requiring, or discouraging any particular treatment.

Competing interests: $\mathrm{G}$. Costamagna's department has received research grants from Cook Medical, Boston Scientific, Olympus, and Taewoong Medical. J. Devière's department has received research support (2010 to 2016) from Boston Scientific and Cook Endoscopy; he was a consultant for Olympus at a meeting in January 2016; and his university holds a pending patent application on a specific guidewire. A. Tringali has provided consultancy for Boston Scientific (one day animal laboratory in 2012 and 2013, speaking and teaching in 2014). J. van Hooft has received research grants from Cook Medical and Abbott, and provided consultancy for Boston Scientific. E. J. Williams has been commissioned by the British Society of Gastroenterology to write national guidelines on management of common bile duct stones. L. Aabakken, M. Arvanitakis, E. Bories, M. Dinis-Ribeiro, J.-M. Dumonceau, M. Giovannini, T. Gyokeres, M. Hafner, J. Halttunen, C. Hassan, L. Lopes, A. Mariani, I. S. Papanikolaou, P. A. Testoni, and T. C. Tham have no competing interests.

\section{Institutions}

1 Division of Gastroenterology and Gastrointestinal Endoscopy, Vita-Salute San Raffaele University-San Raffaele Scientific Institute, Milan, Italy

2 Department of Medicine, Rikshospitalet University Hospital, Oslo, Norway Department of Gastroenterology, Hepatopancreatology and Digestive Oncology, Erasme University Hospital, Université Libre de Bruxelles, Brussels, Belgium

${ }^{4}$ Endoscopic Unit, Paoli-Calmettes Institute, Marseilles, France

${ }^{5}$ Digestive Endoscopy Unit, Università Cattolica del Sacro Cuore, Rome, Italy

${ }^{6}$ Department of Gastroenterology, Instituto Portugues de Oncologia, Porto, Portugal

Gedyt Endoscopy Center, Buenos Aires, Argentina

${ }^{8}$ Department of Gastroenterology, State Health Centre, Budapest, Hungary

${ }^{9}$ Department of Internal Medicine, St. Elisabeth Hospital, Vienna, Austria

${ }^{10}$ Department of Gastrointestinal and General Surgery, Helsinki University Central Hospital, Helsinki, Finland

${ }^{11}$ Department of Gastroenterology, Nuovo Regina Margherita Hospital, Rome, Italy

12 Department of Gastroenterology, Hospital of Santa Luzia, Viana do Castelo, Portugal

13 Hepatogastroenterology Unit, 2nd Department of Internal Medicine and Research Unit, Attikon University General Hospital, University of Athens, Greece

${ }^{14}$ Division of Gastroenterology, Ulster Hospital, Belfast, Northern Ireland

${ }^{15}$ Department of Gastroenterology and Hepatology, Academic Medical Center, Amsterdam, The Netherlands

${ }^{16}$ Department of Gastroenterology, Royal Bournemouth Hospital, Bournemouth, UK 


\section{References}

1 Tse F, Yuan Y, Moayyedi P et al. Guidewire-assisted cannulation of the common bile duct for the prevention of post-endoscopic retrograde cholangiopancreatography (ERCP) pancreatitis. Cochrane Database Syst Rev 2012; 12: CD009662

2 Williams EJ, Taylor S, Fairclough P et al. Are we meeting the standards set for endoscopy? Results of a large-scale prospective survey of endoscopic retrograde cholangio-pancreatograph practice Gut 2007; 56: $821-829$

3 Dumonceau JM, Hassan C, Riphaus A et al. European Society of Gastrointestinal Endoscopy (ESGE) Guideline Development Policy. Endoscopy 2012; 44: 626-629

4 Artifon EL, Sakai P, Cunha JE et al. A Guidewire cannulation reduces risk of post-ERCP pancreatitis and facilitates bile duct cannulation. Am J Gastroenterol 2007; 102: 2147-2153

5 Testoni PA, Mariani A, Giussani A et al. Risk factors for post-ERCP pancreatitis in high- and low-volume centers and among expert and nonexpert operators: a prospective multicenter study. Am J Gastroenterol 2010; $105: 1753-1761$

6 Mariani A, Giussani A, Di Leo M et al. Guidewire biliary cannulation does not reduce post-ERCP pancreatitis compared with the contrast injection technique in low-risk and high-risk patients. Gastrointest Endosc 2012; 75: 339-346

7 Dumonceau JM, Andriulli A, Elmunzer BJ et al. Prophylaxis of post-ERCP pancreatitis: European Society of Gastrointestinal Endoscopy (ESGE) Guideline - updated June 2014. Endoscopy 2014; 46: 799-815

8 Halttunen J, Meisner S, Aabakken L et al. Difficult cannulation as defined by a prospective study of the Scandinavian Association for Digestive Endoscopy (SADE) in 907 ERCPs. Scand J Gastroenterol 2014; 49 $752-758$

9 Freeman ML, DiSario AJ, Nelson DB et al. Risk factors for post-ERCP pancreatitis: a prospective, multicenter study. Gastrointest Endosc 2001; 54: $425-434$

10 Friedland S, Soetikno RM, Vandervoort J et al. Bedside scoring system to predict the risk of developing pancreatitis following ERCP. Endoscopy 2002; 34: 483-488

11 Masci E, Mariani A, Curioni $S$ et al. Risk factors for pancreatitis following endoscopic retrograde cholangiopancreatography: a meta-analysis. Endoscopy 2003; 35: $830-834$

12 Wang P, Li ZS, Liu F et al. Risk factors for ERCP-related complications: a prospective multicenter study. Am J Gastroenterol 2009; 104: 31 - 40

13 Ding $X$, Zhang $F$, Wang $Y$. Risk factors for post-ERCP pancreatitis: A systematic review and meta-analysis. Surgeon 2015; 13: 218-229

14 Verma D, Gostout CJ, Petersen BT et al. Establishing a true assessment of endoscopic competence in ERCP during training and beyond: a singleoperator learning curve for deep biliary cannulation in patients with native papillary anatomy. Gastrointest Endosc 2007; 65: 394-400

15 Baron TH, Petersen BT, Mergener K et al. Quality indicators for endoscopic retrograde cholangiopancreatography. Am J Gastroenterol 2006; 101: $892-897$

16 Guda NM, Freeman ML. Are you safe for your patients - how many ERCPs should you be doing? Endoscopy 2008; 40: 675-676

17 Williams EJ, Taylor S, Fairclough Pet al. Risk factors for complication following ERCP; results of a large-scale, prospective multicenter study. Endoscopy 2007; 39: 793-801

18 Bourke MJ, Costamagna G, Freeman ML. Biliary cannulation during endoscopic retrograde cholangiopancreatography: core technique and recent innovations. Endoscopy 2009; 41: 612-617

19 Laasch HU, Tringali A, Wilbraham L et al. Comparison of standard and steerable catheters for bile duct cannulation in ERCP. Endoscopy 2003; 35: 669-674

20 Lella F, Bagnolo F, Colombo $E$ et al. A simple way of avoiding post-ERCP pancreatitis. Gastrointest Endosc 2004; 59: 830-834

21 Lee TH, Park do H, Park JY et al. Can wire-guided cannulation prevent post-ERCP pancreatitis? A prospective randomized trial Gastrointest Endosc 2009; 69: 444-449

22 Kawakami H, Maguchi H, Mukai T et al. Japan Bile Duct Cannulation Study Group. A multicenter, prospective, randomized study of selective bile duct cannulation performed by multiple endoscopists: the BIDMEN study. Gastrointest Endosc 2012; 75: 362 - 372

23 Katsinelos P, Paroutoglou G, Kountouras J et al. A comparative study of standard ERCP catheter and hydrophilic guide wire in the selective cannulation of the common bile duct. Endoscopy 2008; 40: 302-307
24 Bailey AA, Bourke MJ, Williams SJ et al. A prospective randomized trial of cannulation technique in ERCP: effects on technical success and post-ERCP pancreatitis. Endoscopy 2008; 40: 296-301

$25 \mathrm{Nambu}$ T, Ukita T, Shigoka H et al. Wire-guided selective cannulation of the bile duct with a sphincterotome: a prospective randomized comparative study with the standard method. Scand J Gastroenterol 2011; 46: 109-115

26 Kobayashi G, Fujita N, Imaizumi K et al. Wire-guided biliary cannulation technique does not reduce the risk of post-ERCP pancreatitis: multicenter randomized controlled trial. Dig Endosc 2013; 25: 295 302

27 Cennamo V, Fuccio L, Zagari RM et al. Can a wire guided cannulation technique increase bile duct cannulation rate and prevent post-ERCP pancreatitis? A meta-analysis of randomized controlled trials Am J Gastroenterol 2009; 104: 2343-2350

28 Cheung J, Tsoi KK, Quan WL et al. Guidewire versus conventional contrast cannulation of the common bile duct for the prevention of postERCP pancreatitis: a systematic review and meta-analysis. Gastrointest Endosc 2009; 70: 1211 - 1229

29 Tse F, Yuan Y, Moayyedi P et al. Guidewire-assisted cannulation for the prevention of post-ERCP pancreatitis: a systematic review and meta-analysis. Endoscopy 2013; 45: 605-618

30 Shao LM, Chen QY, Chen MY et al. Can wire-guided cannulation reduce the risk of post-endoscopic retrograde cholangiopancreatography pancreatitis? A meta-analysis of randomized controlled trials J Gastroenterol Hepatol 2009; 24: 1710-1715

31 Cotton PB, Lehman G, Vennes J et al. Endoscopic sphincterotomy complications and their management: an attempt at consensus. Gastrointest Endosc 1991; 37: 383-393

32 Tarnasky PR. Guidewire cannulation: friend or foe. Gastrointest Endosc 2012; 76: 919-920

33 Halttunen J, Kylänpää L. A prospective randomized study of thin versus regular-sized guide wire in wire-guided cannulation. Surg Endosc 2013; $27: 1662-1667$

34 Vihervaara H, Grönroos JM, Koivisto $M$ et al. Angled- or straight-tipped hydrophilic guidewire in biliary cannulation: a prospective, randomized, controlled trial. Surg Endosc 2013; 27: 1281 - 1286

35 Tsuchiya T, Itoi T, Maetani I et al. Effectiveness of the J-Tip guidewire for selective biliary cannulation compared to conventional guidewires (The JANGLE Study). Dig Dis Sci 2015; 60: 2502-2508

36 Tanaka $R$, Itoi $T$, Sofuni $A$ et al. Is the double-guidewire technique superior to the pancreatic duct guidewire technique in cases of pancreatic duct opacification? J Gastroenterol Hepatol 2013; 28: 1787-1793

37 Herreros de Tejada A, Calleja JL, Diaz G et al. Double-guidewire technique for difficult bile duct cannulation: a multicenter randomized controlled trial. Gastrointest Endosc 2009; 70: 700-709

38 Angsuwatcharakon P, Rerknimitr R, Ridtitid $W$ et al. Success rate and cannulation time between precut sphincterotomy and double-guidewire technique in truly difficult biliary cannulation. J Gastroenterol Hepatol 2012; 27: 356-3561

39 Coté GA, Mullady DK, Jonnalagadda SS et al. Use of a pancreatic duct stent or guidewire facilitates bile duct access with low rates of precut sphincterotomy: a randomized clinical trial. Dig Dis Sci 2012; 57: $3271-3278$

40 Maeda S, Hayashi H, Hosokawa $O$ et al. Prospective randomized pilot trial of selective biliary cannulation using pancreatic guide-wire placement. Endoscopy 2003; 35: $721-724$

41 Yoo YW, Cha S-W, Lee WC et al. Double guidewire technique vs transpancreatic precut sphincterotomy in difficult biliary cannulation. World J Gastroenterol 2013; 19: 108 - 114

42 Ito $\mathrm{K}$, Horaguchi J, Fujita $\mathrm{N}$ et al. Clinical usefulness of double-guidewire technique for difficult biliary cannulation in endoscopic retrograde cholangiopancreatography. Dig Endosc 2014; 26: 442 - 449

43 Lee TH, Hwang SO, Choi HJ et al. Sequential algorithm analysis to facilitate selective biliary access for difficult biliary cannulation in ERCP: a prospective clinical study.Feb. BMC Gastroenterol 2014: DOI 10.1186/ 1471-230X-14-30

44 Xinopoulos D, Bassioukas SP, Kypreos D et al. Pancreatic duct guidewire placement for biliary cannulation in a single-session therapeutic ERCP. World J Gastroenterol 2011; 17: 1989-1995

45 Nguyen-Tang T, Dumonceau J-M. Double-guidewire technique for difficult bile duct cannulation: why not insert a prophylactic pancreatic stent? Gastrointest Endosc 2010; 72: 466; author reply 466-467 
46 Ito K, Fujita N, Noda Y et al. Can pancreatic duct stenting prevent postERCP pancreatitis in patients who undergo pancreatic duct guidewire placement for achieving selective biliary cannulation? A prospective randomized controlled trial J Gastroenterol 2010; 45: 1183-1191

47 Nakahara K, Okuse C, Suetani K et al. Need for pancreatic stenting after sphincterotomy in patients with difficult cannulation. World J Gastroenterol 2014; 20: 8617-8623

48 Hisa T. Impact of changing our cannulation method on the incidence of post-endoscopic retrograde cholangiopancreatography pancreatitis after pancreatic guidewire placement. World J Gastroenterol 2011; 17: 5289

$49 \mathrm{Lim}$ JU, Joo KR, Cha JM et al. Early use of needle-knife fistulotomy is safe in situations where difficult biliary cannulation is expected. Dig Dis Sci 2012; 57: $1384-1390$

50 Kaffes AJ, Sriram PVJ, Rao GV et al. Early institution of pre-cutting for difficult biliary cannulation: a prospective study comparing conventional vs. a modified technique. Gastrointest Endosc 2005; 62: 669 674

51 Cennamo V, Fuccio L, Zagari RM et al. Can early precut implementation reduce endoscopic retrograde cholangiopancreatography-related complication risk? Meta-analysis of randomized controlled trials Endoscopy 2010; 42: 381 - 388

52 Gong B, Hao L, Bie L et al. Does precut technique improve selective bile duct cannulation or increase post-ERCP pancreatitis rate? A meta-analysis of randomized controlled trials Surg Endosc 2010; 24: 2670 2680

53 Navaneethan $U$, Konjeti $R$, Venkatesh PG K et al. Early precut sphincterotomy and the risk of endoscopic retrograde cholangio-pancreatography related complications: An updated meta-analysis. World J Gastrointest Endosc 2014; 6: 200-208

54 Choudhary A, Winn J, Siddique S et al. Effect of precut sphincterotomy on post-endoscopic retrograde cholangio-pancreatography pancreatitis: A systematic review and meta-analysis. World J Gastroenterol 2014; 20: 4093 - 4101

55 Swan MP, Alexander S, Moss A et al. Needle knife sphincterotomy does not increase the risk of pancreatitis in patients with difficult biliary cannulation. Clin Gastroenterol Hepatol 2013; 11: 430-436

56 Harewood GC, Baron TH. An assessment of the learning curve for precut biliary sphincterotomy. Am J Gastroenterol 2002; 97: 1708-1712

57 Katsinelos P, Mimidis K, Paroutoglou G et al. Needle-knife papillotomy: a safe and effective technique in experienced hands. Hepatogastroenterology 2004; 51: 349 - 352

58 Robison LS, Varadarajulu S, Wilcox CM. Safety and success of precut biliary sphincterotomy: Is it linked to experience or expertise? World J Gastroenterol 2007; 13: 2183-2186

59 Akaraviputh $T$, Lohsiriwat $V$, Swangsri J et al. The learning curve for safety and success of precut sphincterotomy for therapeutic ERCP: a single endoscopist's experience. Endoscopy 2008; 40: 513-516

60 Fukatsu H, Kawamoto H, Harada $R$ et al. Quantitative assessment of technical proficiency in performing needle-knife precut papillotomy. Surg Endosc 2009; 23: 2066-2072

61 Figueiredo FA, Pelosi AD, Machado $L$ et al. Precut papillotomy: a risky technique not only for experts but also for average endoscopists skilled in ERCP. Dig Dis Sci 2010; 55: $1485-1489$

62 Lee TH, Bang BW, Park SH et al. Precut fistulotomy for difficult biliary cannulation: is it a risky preference in relation to the experience of an endoscopist? Dig Dis Sci 2011; 56: 1896 - 1903

63 Sundaralingam P, Masson P, Bourke MJ et al. Early precut sphincterotomy does not increase risk during endoscopic retrograde cholangiopancreatography in patients with difficult biliary access: a meta-analysis of randomized controlled trials. Clin Gastroenterol Hepatol 2015; 13: $1722-1729$

64 Lopes L, Dinis-Ribeiro M, Rolanda C. Early precut fistulotomy for biliary access: time to change the paradigm of "the later, the better"? Gastrointest Endosc 2014: 80; 634-641

65 Mavrogiannis C, Liatsos C, Romanos A et al. Needle-knife fistulotomy versus needle-knife papillotomy for the treatment of common bile duct stones. Gastrointest Endosc 1999; 50: 334 - 339

66 Katsinelos P, Gkagkalis S, Chatzimavroudis $G$ et al. Comparison of three types of precut technique to achieve common bile duct cannulation: a retrospective analysis of 274 cases. Dig Dis Sci 2012; 57: 3286 - 3292

67 Abu-Hamda EM, Baron TH, Simmons DT et al. A retrospective comparison of outcomes using three different precut needle knife techniques for biliary cannulation. J Clin Gastroenterol 2005; 39: 717-721
68 Horiuchi A, Nakayama Y, Kajiyama M et al. Effect of precut sphincterotomy on biliary cannulation based on the characteristics of the major duodenal papilla. Clin Gastroenterol Hepatol 2007; 9: 1113-1118

69 Testoni PA, Testoni S, Giussani A. Difficult biliary cannulation during ERCP: how to facilitate biliary access and minimize the risk of postERCP pancreatitis. Dig Liver Dis 2011; 43: 596-603

70 Testoni PA, Mariani A, Giussani A et al. Risk factors for post-ERCP pancreatitis in high- and low-volume centers and among expert and nonexpert operators: a prospective multicenter study. Am J Gastroenterol 2010; 105: $1753-1761$

71 Kubota K, Sato T, Kato $S$ et al. Needle-knife precut papillotomy with a small incision over a pancreatic stent improves the success rate and reduces the complication rate in difficult biliary cannulations. J Hepatobiliary Pancreat Sci 2013; 20: $382-388$

72 Cha SW, Leung WD, Lehman GA et al. Does leaving a main pancreatic duct stent in place reduce the incidence of precut biliary sphincterotomy-associated pancreatitis? A randomized, prospective study Gastrointest Endosc 2013; 77: 209-216

73 Madácsy L, Kurucsai G, Fejes $R$ et al. Prophylactic pancreas stenting followed by needle-knife fistulotomy in patients with sphincter of Oddi dysfunction and difficult cannulation: new method to prevent postERCP pancreatitis. Dig Endosc 2009; 21: 8-13

74 Fogel EL, Eversman D, Sherman $S$ et al. Sphincter of Oddi dysfunction : pancreaticobiliary sphincterotomy with pancreatic stent placement has a lower rate of pancreatitis than biliary sphincterotomy alone. Endoscopy 2002; 34: 280 - 285

75 Varadarajulu S, Wilcox CM. Randomized trial comparing needle-knife and pull-sphincterotome techniques for pancreatic sphincterotomy in high-risk patients. Gastrointest Endosc 2006; 64: 716-722

76 Lawrence C, Romagnuolo J, Cotton PB et al. Post-ERCP pancreatitis rates do not differ between needle-knife and pull-type pancreatic sphincterotomy techniques: a multiendoscopist 13-year experience. Gastrointest Endosc 2009; 69: 1271 - 1275

77 Attwell A, Borak G, Hawes $R$ et al. Endoscopic pancreatic sphincterotomy for pancreas divisum by using a needle-knife or standard pulltype technique: safety and reintervention rates. Gastrointest Endosc 2006; 64: 705 - 711

78 Coté GA, Ansstas M, Pawa R et al. Difficult biliary cannulation: use of physician-controlled wire-guided cannulation over a pancreatic duct stent to reduce the rate of precut sphincterotomy (with video). Gastrointest Endosc 2010; 71: 275 - 279

79 Afghani E, Akshintala VS, Khashab MA et al. 5-Fr vs. 3-Fr pancreatic stents for the prevention of post-ERCP pancreatitis in high-risk patients: a systematic review and network meta-analysis. Endoscopy 2014; 46: $573-580$

80 Goff JS. Common bile duct pre-cut sphincterotomy: transpancreatic sphincter approach. Gastrointest Endosc 1995; 41: 502-506

81 Zang J, Zhang C, Gao J. Guidewire-assisted transpancreatic sphincterotomy for difficult biliary cannulation: a prospective randomized controlled trial. Surg Laparosc Endosc Percutan Tech 2014; 24: 429-433

82 Chun CG, Cha S-W, Kim SH et al. DGT vs. TPS in patients with initial PD cannulation by chance: prospective randomized multicenter study. Gastrointest Endosc 2012; 75: AB141

83 Catalano MF, Linder JD, Geenen JE. Endoscopic transpancreatic papillary septotomy for inaccessible obstructed bile ducts: comparison with standard pre-cut papillotomy. Gastrointest Endosc 2004; 60: $557-561$

84 Kahaleh M, Tokar J, Mullick T et al. Prospective evaluation of pancreatic sphincterotomy as a precut technique for biliary cannulation. Clin Gastroenterol Hepatol 2004; 2: 971 -977

85 Lee YJ, Park YK, Lee MJ et al. Different strategies for transpancreatic septotomy and needle knife infundibulotomy due to the presence of unintended pancreatic cannulation in difficult biliary cannulation. Gut Liver 2015; 9: 534-539

86 Halttunen J, Keranen I, Udd M et al. Pancreatic sphincterotomy versus needle knife precut in difficult biliary cannulation. Surg Endosc 2009; 23: $745-749$

87 Katsinelos P, Gkagkalis S, Chatzimavroudis $G$ et al. Comparison of three types of precut technique to achieve common bile duct cannulation: a retrospective analysis of 274 cases. Dig Dis Sci 2012; 57: 3286 - 3292

88 Wang $P$, Zhang W, Liu F et al. Success and complication rates of two precut techniques, transpancreatic sphincterotomy and needle-knife sphincterotomy for bile duct cannulation. J Gastrointest Surg 2010; 14: 697-704 
89 Kohler A, Maier M, Benz C et al. A new HF current generator with automatically controlled system (Endocut mode) for endoscopic sphincterotomy - preliminary experience. Endoscopy 1998; 30: $351-355$

90 Akiho H, Sumida Y, Akahoshi Ket al. Safety advantage of endocut mode over endoscopic sphincterotomy for choledocholithiasis. World J Gastroenterol 2006; 12: 2086-2018

91 Perini RF, Sadurski R, Cotton PB et al. Post-sphincterotomy bleeding after the introduction of microprocessor controlled electrosurgery: does the new technology make the difference? Gastrointest Endosc 2005; 61: $53-57$

92 Tanaka $Y$, Sato $K$, Tsuchida $H$ et al. A prospective randomized controlled study of endoscopic sphincterotomy with the endocut mode or conventional blended cut mode. J Clin Gastroenterol 2015; 49: 127-131

93 Parlak E, Koksal AS, Ozlas E et al. Is there a safer electrosurgical current for endoscopic sphincterotomy in patients with liver cirrhosis? Wien Klin Wochenschr 2015: DOI 10.1007/s00508-014-0677-3

94 Stefanidis $G$, Karamanolis $G$, Viazis $N$ et al. A comparative study of postendoscopic sphincterotomy complications with various types of electrosurgical current in patients with choledocholithiasis. Gastrointest Endosc 2003; 57: 192 - 197

95 Elta GH, Barnett JL, Wille RT et al. Pure cut electrocautery current for sphincterotomy causes less post-procedure pancreatitis than blended current. Gastrointest Endosc 1998; 47: 149-153

96 Macintosh DG, Love J, Abraham NS. Endoscopic sphincterotomy by using pure-cut electrosurgical current and the risk of post-ERCP pancreatitis: a prospective randomized trial. Gastrointest Endosc 2004; 60: $551-556$

97 Norton ID, Petersen BT, Bosco J et al. A randomized trial of endoscopic biliary sphincterotomy using pure-cut versus combined cut and coagulation waveforms. Clin Gastroenterol Hepatol 2005; 3: 1029-1033

98 Gorelick A, Cannon M, Barnett J et al. First cut, then blend: an electrocautery technique affecting bleeding at sphincterotomy. Endoscopy 2001; 33: 976-980

99 Verma D, Kapadia A, Adler DG. Pure versus mixed electrosurgical current for endoscopic biliary sphincterotomy: a meta-analysis of adverse outcomes. Gastrointest Endosc 2007; 66: 283-290

100 Liao $W$-C, Tu Y-K, Wu M-S et al. Balloon dilation with adequate duration is safer than sphincterotomy for extracting bile duct stones: a systematic review and meta-analyses. Clin Gastroenterol Hepatol 2012; 10: 1101 - 1109

101 Liu Y, Su P, Lin S et al. Endoscopic papillary balloon dilatation versus endoscopic sphincterotomy in the treatment for choledocholithiasis: a meta-analysis. J Gastroenterol Hepatol 2012; 27: 464-461

102 Zhao $\mathrm{H}$-C. Meta-analysis comparison of endoscopic papillary balloon dilatation and endoscopic sphincteropapillotomy. World J Gastroenterol 2013; 19: 3883-3891

103 Liao W-C, Lee C-T, Chang C-Y et al. Randomized trial of 1-minute versus 5-minute endoscopic balloon dilation for extraction of bile duct stones. Gastrointest Endosc 2010; 72: 1154-1162

104 Isayama $H$, Komatsu $Y$, Inoue $Y$ et al. Preserved function of the Oddi sphincter after endoscopic papillary balloon dilation. Hepatogastroenterology 2003; 50: 1787-1791

105 Disario JA, Freeman ML, Bjorkman DJ et al. Endoscopic balloon dilation compared with sphincterotomy for extraction of bile duct stones. Gastroenterology 2004; 127: 1291 - 1299

106 Fujita N, Maguchi H, Komatsu Y et al. Endoscopic sphincterotomy and endoscopic papillary balloon dilatation for bile duct stones: A prospective randomized controlled multicenter trial. Gastrointest Endosc 2003; 57: 151 - 155

107 Seo YR, Moon JH, Choi HJ et al. Comparison of endoscopic papillary balloon dilation and sphincterotomy in young patients with CBD stones and gallstones. Dig Dis Sci 2014; 59: 1042 - 1047

108 Oh MJ, Kim TN. Prospective comparative study of endoscopic papillary large balloon dilation and endoscopic sphincterotomy for removal of large bile duct stones in patients above 45 years of age. Scand J Gastroenterol 2012; 47: 1071-1077

109 Lin CK, Lai KH, Chan HH et al. Endoscopic balloon dilatation is a safe method in the management of common bile duct stones. Dig Liver Dis 2004; 36: $68-72$

110 Vlavianos P, Chopra K, Mandalia S et al. Endoscopic balloon dilatation versus endoscopic sphincterotomy for the removal of bile duct stones: a prospective randomised trial. Gut 2003; 52: 1165-1169
111 Minakari M, Samani RR, Shavakhi A et al. Endoscopic papillary balloon dilatation in comparison with endoscopic sphincterotomy for the treatment of large common bile duct stone. Adv Biomed Res 2013; 2: 46 DOI 10.4103/2277-9175.114186

112 Arnold JC, Benz C, Martin WR et al. Endoscopic papillary balloon dilation vs. sphincterotomy for removal of common bile duct stones: a prospective randomized pilot study. Endoscopy 2001; 33: 563-567

113 Bergman JJ, Rauws EA, Fockens $P$ et al. Randomised trial of endoscopic balloon dilation versus endoscopic sphincterotomy for removal of bileduct stones. Lancet 1997; 349: $1124-9$

114 Minami A, Nakatsu T, Uchida $N$ et al. Papillary dilation vs sphincterotomy in endoscopic removal of bile duct stones. A randomized trial with manometric function. Dig Dis Sci 1995; 40: 2550-2554

115 Natsui M, Narisawa R, Motoyama $H$ et al. What is an appropriate indication for endoscopic papillary balloon dilation? Eur J Gastroenterol Hepatol 2002; 14: 635-640

116 Ochi Y, Mukawa K, Kiyosawa $\mathrm{K}$ et al. Comparing the treatment outcomes of endoscopic papillary dilation and endoscopic sphincterotomy for removal of bile duct stones. J Gastroenterol Hepatol 1999; 14: $90-96$

117 Tanaka S, Sawayama T, Yoshioka T. Endoscopic papillary balloon dilation and endoscopic sphincterotomy for bile duct stones: long-term outcomes in a prospective randomized controlled trial. Gastrointest Endosc 2004; 59: 614-618

118 Yasuda I, Tomita E, Enya $M$ et al. Can endoscopic papillary balloon dilation really preserve sphincter of Oddi function? Gut 2001; 49: 686-691

119 Aiura K, Kitagawa Y. Current status of endoscopic papillary balloon dilation for the treatment of bile duct stones. J Hepatobiliary Pancreat Sci 2011; 18: 339-345

120 Baron TH, Harewood GC. Endoscopic balloon dilation of the biliary sphincter compared to endoscopic biliary sphincterotomy for removal of common bile duct stones during ERCP: a metaanalysis of randomized, controlled trials. Am J Gastroenterol 2004; 99: 1455-1460

121 Weinberg BM, Shindy W, Lo S. Endoscopic balloon sphincter dilation (sphincteroplasty) versus sphincterotomy for common bile duct stones. Cochrane Database Syst Rev 2006: Oct 18; (4) CD004890

122 Mac Mathuna P, Siegenberg D, Gibbons D et al. The acute and longterm effect of balloon sphincteroplasty on papillary structure in pigs. Gastrointest Endosc 1996; 44: 650-655

123 Natsui M, Saito Y, Abe S et al. Long-term outcomes of endoscopic papillary balloon dilation and endoscopic sphincterotomy for bile duct stones. Dig Endosc 2013; 25: 313 - 321

124 Doi S, Yasuda I, Mukai T et al. Comparison of long-term outcomes after endoscopic sphincterotomy versus endoscopic papillary balloon dilation: a propensity score-based cohort analysis. J Gastroenterol 2012; 48: 1090-1096

125 Akbar A, Abu Dayyeh BK, Baron TH et al. Rectal nonsteroidal anti-inflammatory drugs are superior to pancreatic duct stents in preventing pancreatitis after endoscopic retrograde cholangiopancreatography: a network meta-analysis. Clin Gastroenterol Hepatol 2013; 11: $778-783$

126 Aizawa T, Ueno N. Stent placement in the pancreatic duct prevents pancreatitis after endoscopic sphincter dilation for removal of bile duct stones. Gastrointest Endosc 2001; 54: 209-213

127 Delhaye M, Matos C, Devière J. Endoscopic management of chronic pancreatitis. Gastrointest Endosc Clin N Am 2003; 13: 717-742

128 Bakman Y, Freeman ML. Update on biliary and pancreatic sphincterotomy. Curr Opin Gastroenterol 2012; 28: 420-426

129 Buscaglia JM, Kalloo AN. Pancreatic sphincterotomy: technique, indications, and complications. World J Gastroenterol 2007; 13: 4064 4071

130 Brugge WR. Endoscopic approach to the diagnosis and treatment of pancreatic disease. Curr Opin Gastroenterol 2013; 29: 559-565

131 Cotton PB, Durkalski V, Romagnuolo J et al. Effect of endoscopic sphincterotomy for suspected sphincter of Oddi dysfunction on pain-related disability following cholecystectomy: the EPISOD randomized clinical trial. JAMA 2014; 311: 2101 -2109

132 Kozarek RA, Ball TJ, Patterson DJ et al. Endoscopic pancreatic duct sphincterotomy: indications, technique, and analysis of results. Gastrointest Endosc 1994; 40: $592-598$

133 Cremer M, Devière J, Delhaye $M$ et al. Stenting in severe chronic pancreatitis: results of medium-term follow-up in seventy-six patients. Endoscopy 1991; 23: $171-176$ 
134 Kim MH, Myung SJ, Kim YS et al. Routine biliary sphincterotomy may not be indispensable for endoscopic pancreatic sphincterotomy. Endoscopy 1998; 30: 697-701

135 Jakobs R, Reimann JF. Is there a need for dual sphincterotomy in patients with chronic pancreatitis? Endoscopy 2003; 35: 250-251

136 Boix J, Lorenzo-Zuniga $V$, Ananos $F$ et al. Impact of periampullary duodenal diverticula at endoscopic retrograde cholangiopancreatography: a proposed classification of periampullary duodenal diverticula. Surg Laparosc Endosc Percutan Tech 2006; 16: 208-211

137 Egawa N, Anjiki H, Takuma Ket al. Juxtapapillary duodenal diverticula and pancreatobiliary disease. Dig Surg 2010; 27: 105 - 109

138 Cappell MS, Mogrovejo E, Manickam Pet al. Endoclips to facilitate cannulation and sphincterotomy during ERCP in a patient with an ampulla within a large duodenal diverticulum: case report and literature review. Dig Dis Sci 2015; 60: 168 -173

139 Fogel EL, Sherman S, Lehman GA. Increased selective biliary cannulation rates in the setting of periampullary diverticula: main pancreatic duct stent placement followed by pre-cut biliary sphincterotomy. Gastrointest Endosc 1998; 47: 396-400

140 Park CS, Park CH, Koh HR et al. Needle-knife fistulotomy in patients with periampullary diverticula and difficult bile duct cannulation. J Gastroenterol Hepatol 2012; 27: 1480-1483

141 Myung DS, Park CH, Koh HR et al. Cap-assisted ERCP in patients with difficult cannulation due to periampullary diverticulum. Endoscopy 2014; 46: 352 - 355

142 Vaira D, Dowsett JF, Hatfield AR et al. Is duodenal diverticulum a risk factor for sphincterotomy? Gut 1989; 30: 39-42

143 Tham TC, Kelly M. Association of periampullary duodenal diverticula with bile duct stones and with technical success of endoscopic retrograde cholangiopancreatography. Endoscopy 2004; 36: 1050-1053

144 Liao WC, Huang SP, Wu MS et al. Comparison of endoscopic papillary balloon dilatation and sphincterotomy for lithotripsy in difficult sphincterotomy. J Clin Gastroenterol 2008; 42: 295-299

145 Kim HW, Kang DH, Choi CW et al. Limited endoscopic sphincterotomy plus large balloon dilation for choledocholithiasis with periampullary diverticula. World J Gastroenterol 2010; 16: 4335 - 4340

$146 \mathrm{Kim} \mathrm{KY,} \mathrm{Han} \mathrm{J,} \mathrm{Kim} \mathrm{HG} \mathrm{et} \mathrm{al.} \mathrm{Late} \mathrm{complications} \mathrm{and} \mathrm{stone} \mathrm{recurrence}$ rates after bile duct stone removal by endoscopic sphincterotomy and large balloon dilation are similar to those after endoscopic sphincterotomy alone. Clin Endosc 2013; 46: 637-642

147 Kirk AP, Summerfield JA. Incidence and significance of juxtapapillary diverticula at endoscopic retrograde cholangiopancreatography. Digestion 1980; $20: 31-35$

148 Chang-Chien CS. Do juxtapapillary diverticula of the duodenum interfere with cannulation at endoscopic retrograde cholangiopancreatography? A prospective study Gastrointest Endosc 1987; 33: 298 - 300

149 Katsinelos $P$, Chatzimavroudis $G$, Tziomalos $K$ et al. Impact of periampullary diverticula on the outcome and fluoroscopy time in endoscopic retrograde cholangiopancreatography. Hepatobiliary Pancreat Dis Int 2013; 12: $408-414$

150 Panteris $V$, Vezakis A, Filippou $G$ et al. Influence of juxtapapillary diverticula on the success or difficulty of cannulation and complication rate. Gastrointest Endosc 2008; 68: 903 -910

151 Tyagi $P$, Sharma $P$, Sharma $B C$ et al. Periampullary diverticula and technical success of endoscopic retrograde cholangiopancreatography. Surg Endosc 2009; 23: 1342 - 1345

152 Mohammad Alizadeh AH, Afzali ES, Shahnazi A et al. ERCP features and outcome in patients with periampullary duodenal diverticulum. ISRN Gastroenterol 2013: DOI 10.1155/2013/217261

153 Balik E, Eren T, Keskin $M$ et al. Parameters that may be used for predicting failure during endoscopic retrograde cholangiopancreatography. J Oncol 2013: DOI 10.1155/2013/201681

154 Williams EJ, Ogollah $R$, Thomas $P$ et al. What predicts failed cannulation and therapy at ERCP? Results of a large-scale multicenter analysis Endoscopy 2012; 44: 674-683

155 Williams EJ, Taylor S, Fairclough $P$ et al. Risk factors for complication following ERCP; results of a large-scale, prospective multicenter study. Endoscopy 2007; 39: 793 - 801

156 Wang P, Li ZS, Liu F et al. Risk factors for ERCP-related complications: a prospective multicenter study. Am J Gastroenterol 2009; 104: 31 - 40

157 DiMagno MJ, Wamsteker EJ. Pancreas divisum. Curr Gastroenterol Rep 2011; 13: 150 - 156

158 Fogel EL, Toth TG, Lehman GA et al. Does endoscopic therapy favorably affect the outcome of patients who have recurrent acute pancreatitis and pancreas divisum? Pancreas 2007; 34: 21 - 45
159 Devereaux BM, Fein S, Purich E et al. A new synthetic porcine secretin for facilitation of cannulation of the dorsal pancreatic duct at ERCP in patients with pancreas divisum: a multicenter, randomized, doubleblind comparative study. Gastrointest Endosc 2003; 57: 643-647

160 Park SH, de Bellis M, McHenry L et al. Use of methylene blue to identify the minor papilla or its orifice in patients with pancreas divisum. Gastrointest Endosc 2003; 57: 358 - 363

161 Cai Q Keilin S, Obideen K et al. Intraduodenal hydrochloric acid infusion for facilitation of cannulation of the dorsal pancreatic duct at ERCP in patients with pancreas divisum: a preliminary study. Am J Gastroenterol 2010; 105: 1450-1451

162 Alazmi WM, Mosler P, Watkins JL et al. Predicting pancreas divisum by inspection of the minor papilla: a prospective study. J Clin Gastroenterol 2007; 41: $422-426$

163 Lawrence C, Stefan AM, Howell DA. Endoscopic appearance of the minor papilla predicts findings at pancreatography. Dig Dis Sci 2010; 55: $2412-2416$

164 Matos C, Metens T, Devière J et al. Pancreas divisum: evaluation with secretin-enhanced magnetic resonance cholangiopancreatography. Gastrointest Endosc 2001; 53: 728-733

165 Attwell A, Borak G, Hawes $R$ et al. Endoscopic pancreatic sphincterotomy for pancreas divisum by using a needle-knife or standard pulltype technique: safety and reintervention rates. Gastrointest Endosc 2006; 64: 705-711

166 Maple JT, Keswani RN, Edmundowicz SA et al. Wire-assisted access sphincterotomy of the minor papilla. Gastrointest Endosc 2009; 69: 47-54

167 Yamamoto $N$, Isayama $H$, Sasahira $N$ et al. Endoscopic minor papilla balloon dilation for the treatment of symptomatic pancreas divisum. Pancreas 2014; 43: 927 - 930

168 Basso N, Pizzuto G, Surgo D et al. Laparoscopic cholecystectomy and intraoperative endoscopic sphincterotomy in the treatment of cholecysto-choledocholithiasis. Gastrointest Endosc 1999; 50: 532 - 535

169 Nakajima $H$, Okubo $H$, Masuko $Y$ et al. Intraoperative endoscopic sphincterotomy during laparoscopic cholecystectomy. Endoscopy 1996; 28: 264

170 Lella F, Bagnolo F, Rebuffat C et al. Use of the laparoscopic-endoscopic approach, the so-called "rendezvous" technique, in cholecystocholedocholithiasis: a valid method in cases with patient-related risk factors for post-ERCP pancreatitis. Surg Endosc 2006; 20: 419-423

171 Tzovaras G, Baloyiannis I, Zachari E et al. Laparoendoscopic rendezvous versus preoperative ERCP and laparoscopic cholecystectomy for the management of cholecysto-choledocholithiasis: interim analysis of a controlled randomized trial. Ann Surg 2012; 255: 435 - 439

172 Morino $M$, Baracchi F, Miglietta $C$ et al. Preoperative endoscopic sphincterotomy versus laparoendoscopic rendezvous in patients with gallbladder and bile duct stones. Ann Surg 2006; 244: 889-896

173 Rábago LR, Vicente C, Soler F et al. Two-stage treatment with preoperative endoscopic retrograde cholangiopancreatography (ERCP) compared with single-stage treatment with intraoperative ERCP for patients with symptomatic cholelithiasis with possible choledocholithiasis. Endoscopy 2006; 38: 779-786

174 El Geidie AA, ElEbidy GK, Naeem YM. Preoperative versus intraoperative endoscopic sphincterotomy for management of common bile duct stones. Surg Endosc 2011; 25: 1230-1237

175 Wang B, Guo Z, Liu Z et al. Preoperative versus intraoperative endoscopic sphincterotomy in patients with gallbladder and suspected common bile duct stones: system review and meta-analysis. Surg Endosc 2013; 27: 2454-2465

176 Arezzo A, Vettoretto N, Famiglietti $F$ et al. Laparoendoscopic rendezvous reduces perioperative morbidity and risk of pancreatitis. Surg Endosc 2013; 27: 1055-1060

177 Gurusamy K, Sahay SJ, Burroughs AK et al. Systematic review and meta-analysis of intraoperative versus preoperative endoscopic sphincterotomy in patients with gallbladder and suspected common bile duct stones. Br J Surg 2011; 98: 908 -916

178 Nagaraja V, Eslick GD, Cox MR. Systematic review and meta-analysis of minimally invasive techniques for the management of cholecystocholedocholithiasis. Hepatobiliary Pancreat Sci 2014; 21: 896-901

179 Leng J-J, Zhang N, Dong $\mathrm{J}-\mathrm{H}$. Percutaneous transhepatic and endoscopic biliary drainage for malignant biliary tract obstruction: a meta-analysis. World J Surg Oncol 2014; 12: 272

180 Fabbri C, Luigiano C, Lisotti A et al. Endoscopic ultrasound-guided treatments: Are we getting evidence based - a systematic review. World J Gastroenterol 2014; 20: 8424-8448 
181 Gupta K, Perez-Miranda M, Kahaleh M et al. Endoscopic ultrasoundassisted bile duct access and drainage: multicenter, long-term analysis of approach, outcomes, and complications of a technique in evolution. J. Clin Gastroenterol 2014; 48: 80-87

182 Artifon ELA, Aparicio D, Paione JB et al. Biliary drainage in patients with unresectable, malignant obstruction where ERCP fails: endoscopic ultrasonography-guided choledochoduodenostomy versus percutaneous drainage. J Clin Gastroenterol 2012; 46: 768 - 774

183 Khashab MA, Valeshabad AK, Afghani E et al. A comparative evaluation of EUS-guided biliary drainage and percutaneous drainage in patients with distal malignant biliary obstruction and failed ERCP. Dig Dis Sci 2015; 60: 557-565

184 Bapaye A, Dubale N, Aher A. Comparison of endosonography-guided vs. percutaneous biliary stenting when papilla is inaccessible for ERCP. United European Gastroenterol J 2013; 1: 285 - 293

185 Dhir V, Itoi T, Khashab MA et al. Multicenter comparative evaluation of endoscopic placement of expandable metal stents for malignant distal common bile duct obstruction by ERCP or EUS-guided approach. Gastrointest Endosc 2015; 81: 913-923

$186 \mathrm{Kim} \mathrm{MH}$, Lee SK, Lee MH et al. Endoscopic retrograde cholangiopancreatography and needle-knife sphincterotomy in patients with Billroth II gastrectomy: a comparative study of the forward-viewing endoscope and the side-viewing duodenoscope. Endoscopy 1997; 29: $82-85$

187 Lin LF, Siauw CP, Ho KS et al. ERCP in post-Billroth II gastrectomy patients: emphasis on technique. Am J Gastroenterol 1999; 94: 144148

188 Aabakken L, Holthe B, Sandstad O et al. Endoscopic pancreaticobiliary procedures in patients with a Billroth II resection: a 10-year followup study. Ital J Gastroenterol Hepatol 1998; 30: 301 - 305
189 Hintze RE, Veltzke W, Adler A et al. Endoscopic sphincterotomy using an S-shaped sphincterotome in patients with a Billroth II or Roux-enY gastrojejunostomy. Endoscopy 1997; 29: 74-78

190 Ciçek B, Parlak E, Dişibeyaz S et al. Endoscopic retrograde cholangiopancreatography in patients with Billroth II gastroenterostomy. J Gastroenterol Hepatol 2007; 22: 1210-1213

191 Bove V, Tringali A, Familiari P et al. ERCP in patients with prior Billroth II gastrectomy: report of 30 years' experience. Endoscopy 2015; 47: $611-616$

192 Jang HW, Lee KJ, Jung MJ et al. Endoscopic papillary large balloon dilatation alone is safe and effective for the treatment of difficult choledocholithiasis in cases of Billroth II gastrectomy: a single center experience. Dig Dis Sci 2013; 58: 1737-43

193 Cheng CL, Liu NJ, Tang JH et al. Double-balloon enteroscopy for ERCP in patients with Billroth II anatomy: results of a large series of papillary large-balloon dilation for biliary stone removal. Endosc Int Open 2015; 3: E216 -E222

194 Shimatani M, Matsushita M, Takaoka M et al. Effective "short" doubleballoon enteroscope for diagnostic and therapeutic ERCP in patients with altered gastrointestinal anatomy: a large case series. Endoscopy 2009; 41: 849-854

195 Itoi T, Ishii K, Sofuni A et al. Large balloon dilatation following endoscopic sphincterotomy using a balloon enteroscope for the bile duct stone extractions in patients with Roux-en-Y anastomosis. Dig Liver Dis 2011; 43: 237-241

196 Moreels TG. Altered anatomy: enteroscopy and ERCP procedures. Best Pract Clin Res Clin Gastroenterol 2012; 26: 347-357

197 Skinner M, Popa D, Neumann $H$ et al. ERCP with the overtube-assisted enteroscopy technique: a systematic review. Endoscopy 2014; 46: $560-572$

Appendix e1, e2

online content viewable at:

http://dx.doi.org/10.1055/s-0042-108641 